This item was submitted to Loughborough's Research Repository by the author.

Items in Figshare are protected by copyright, with all rights reserved, unless otherwise indicated.

\title{
Dry vs. wet: Properties and performance of collagen films. Part II. Cyclic and time-dependent behaviours
}

PLEASE CITE THE PUBLISHED VERSION

https://doi.org/10.1016/j.jmbbm.2020.104040

PUBLISHER

Elsevier

VERSION

AM (Accepted Manuscript)

\section{PUBLISHER STATEMENT}

This paper was accepted for publication in the journal Journal of the Mechanical Behavior of Biomedical Materials and the definitive published version is available at https://doi.org/10.1016/j.jmbbm.2020.104040.

\section{LICENCE}

CC BY-NC-ND 4.0

\section{REPOSITORY RECORD}

Bose, Shirsha, Simin Li, Elisa Mele, and Vadim Silberschmidt. 2020. "Dry Vs. Wet: Properties and Performance of Collagen Films. Part II. Cyclic and Time-dependent Behaviours". Loughborough University. https://hdl.handle.net/2134/12907163.v1. 


\title{
Dry vs. wet: Properties and performance of collagen films. Part II. Cyclic and time-dependent behaviours
}

\author{
Shirsha Bose ${ }^{\mathrm{a}}$, Simin $\mathrm{Li}^{\mathrm{a}}$, Elisa Mele ${ }^{\mathrm{b}}$, Vadim V. Silberschmidt ${ }^{\mathrm{a}, *}$ \\ ${ }^{\text {a } W o l f s o n ~ S c h o o l ~ o f ~ M e c h a n i c a l, ~ E l e c t r i c a l ~ a n d ~ M a n u f a c t u r i n g ~ E n g i n e e r i n g, ~ L o u g h b o r o u g h ~ U n i v e r s i t y, ~ L o u g h b o r o u g h, ~ L e i c e s t e r s h i r e ~ L E 11 ~ 3 T U, ~ U K ~}$ \\ ${ }^{\mathrm{b}}$ Department of Materials, Loughborough University, Loughborough, Leicestershire LE113TU, UK
}

A B S T R A C T

\begin{abstract}
Collagen constitutes one-third of human-body proteins, providing mechanical strength and structural stability. Films of collagen are widely used in tissue engineering as scaffolds for wound healing and corneal implants, among other applications, presupposing the investigation of their mechanical properties and performance under various loading and environmental conditions. Part I of this research (Bose et al., 2020) demonstrated a drastic change in the mechanical response of collagen films under in-aqua conditions when compared to dry specimens. It was also observed that collagen films exhibited a strain-rate-dependent hardening behaviour with a strain-ratesensitivity exponent ranging from 0.02 to 0.2 . In Part II, the cyclic and time-dependent behaviours of collagen films were analysed under different loading and environmental conditions. Strain ratchetting was observed for collagen subjected to cyclic loading under various stress levels and environmental (in-air and in-aqua) conditions, while the in-aqua samples demonstrated an increase in the stiffness ( $50 \%$ in the first cycle), which may be referred to as cyclic stiffening. In contrast, the dry samples showed a drop in the modulus after the first cycle, without any subsequent changes. Additionally, time-dependent viscoelastic properties were analysed, using dynamic mechanical analysis as well as creep and stress-relaxation techniques. Tan $\delta$ values for dry samples ranged from 0.05 to 0.075 , while for hydrated ones it varied from 0.12 to 0.24 . Collagen films exhibited primary and secondary creep stages, while the initial stress-relaxation was fast followed by a monotonous decay. The stress-strain-time data obtained from experiments were fitted in Prony series to estimate the relaxation moduli and times.
\end{abstract}

\author{
Keywords: \\ Collagen \\ Environmental conditions \\ Unloading modulus \\ $\operatorname{Tan} \delta$ \\ Creep \\ Stress relaxation \\ Prony series
}

\section{Introduction}

Collagen is one of the most important proteins present in human body, contributing to the mechanical strength and structural integrity of connective tissues (Fratzl, 2008; Kadler et al., 2007; Buehler, 2006a,b). It has a complex hierarchical building blocks (see details in Part I of this study) beginning with tropocollagen molecules (1.5 nm diameter), assembled in collagen fibrils (100-500 nm diameter). The collagen fibrils, in turn, bundle up to form collagen fibres (few micrometres in diameter) and tissues (millimetres to centimetres) (Gautieri et al., 2011). This hierarchical order defines the complex viscoelastic behaviour of collagenous materials. Importantly, collagen films have significant applications in tissue regeneration such as corneal and wound healing (Ber et al., 2005; Sang et al., 2017; Li et al., 2019; Liu et al., 2012, 2014), substrates for sustained release of hormones (Maeda et al., 2001), dural substitutes (Collins et al., 1991), flexible electronics (Moreno et al.,
2015; Ghosh and Mandal, 2017) etc. thanks to their biocompatibility, biodegradability, flexibility and mechanical strength (Lee and Mooney, 2001; Fratzl, 2008). These potential biomedical applications and complex hierarchical structure mean that collagen-based materials are often exposed to various inelastic and time-dependent deformations under different environmental conditions.

The previous experiments has established that repeated cyclic stretching had a profound influence on mechanical properties of collagen-rich tissues such as skin (Kang and Wu, 2011; Remache et al., 2018; Pissarenko et al., 2019), tendons (Su et al., 2008), bones (Abdel-Wahab et al., 2011) etc. Collagenous tissues usually depict a complex visco-elastic behaviour: an increase in the accumulation of residual strain can lead to damage of the skin tissues (Kang and Wu, 2011; Remache et al., 2018) or increase in energy dissipation (Pissarenko et al., 2019). Some studies suggested that collagenous materials exhibited an increase in the stiffness following cyclic loadings (Su et al.,

\footnotetext{
* Corresponding author.

E-mail address: v.silberschmidt@lboro.ac.uk (V.V. Silberschmidt).
} 
Table 1

Different environmental conditions used in cyclic and DMA test.

\begin{tabular}{lll}
\hline Specimen name & Testing environment & Specimen conditioning \\
\hline $\mathrm{Col}_{\mathrm{D}}$ & Ambient (dry) & - \\
$\mathrm{Col}_{\mathrm{A}}$ & In-aqua & Pre-hydrated (10 min, water) \\
$\mathrm{Col}_{\mathrm{H}}$ & Ambient & Pre-hydrated (10 min, water) \\
\hline
\end{tabular}

Table 2

Comparison of $\tan \delta$ values of collagen from literature and current study.

\begin{tabular}{|c|c|c|c|}
\hline Specimen Type & Dry State & Wet State & Reference \\
\hline Corneal collagen & $0.032-0.06$ & & $\begin{array}{l}\text { Hatami-Marbini and } \\
\text { Rahimi (2015) }\end{array}$ \\
\hline $\begin{array}{l}\text { Corneal collagen } \\
\text { (cross-linked) }\end{array}$ & $0.028-0.048$ & & $\begin{array}{l}\text { Hatami-Marbini and } \\
\text { Rahimi (2015) }\end{array}$ \\
\hline $\begin{array}{l}\text { Porcine stratum } \\
\text { corneum }\end{array}$ & 0.1 & 0.25 & Yuan and Verma (2006) \\
\hline Bovine cortical bone & $0.035-0.1$ & & Abdel-Wahab et al. (2011) \\
\hline Femora of mouse & $0.01-0.04$ & $0.12-0.16$ & Pathak et al. (2011) \\
\hline This study & $0.05-0.075$ & $0.12-0.24$ & \\
\hline
\end{tabular}

2008; Susilo et al., 2016), whereas, in collagen fibrils, the stiffness was nearly constant throughout the entire mechanical cycling (Liu et al., 2018). Thus, it would be interesting to investigate the mechanical response of pure collagen films under different loading (low-, intermediate- and high-stress regimes) and environmental conditions.

To analyse the time-dependent viscoelastic behaviour of collagenbased materials dynamic mechanical analysis (DMA) was used for tissues such as chordae (Wilcox et al., 2014), porcine and bovine cornea (Yuan and Verma, 2006; Hatami-Marbini and Rahimi, 2015), bones (Abdel-Wahab et al., 2011; Pathak et al., 2011), chicken collagen films (Oechsle et al., 2017) etc. Chordal tissues exhibited time-dependent storage modulus but a time-independent loss modulus (Wilcox et al., 2014). Further studies (Hatami-Marbini and Rahimi, 2015; Oechsle et al., 2017) suggested that the storage and loss moduli may be affected by treatment with various crosslinkers or incorporation of other protein sources/salts. Moreover, hydration can influence the damping coefficient, causing a significant change in storage and loss moduli, as observed in wet collagenous corneal tissues (Yuan and Verma, 2006) and bones (Pathak et al., 2011), leading to a drastic change in tan delta (Table 2). Hence, estimating the tan-delta values of pure collagen film in the dry and wet/hydrated state is important.

Another approach to analyse time-dependent properties of collagen is by means of creep and stress-relaxation tests. Previous studies on collagen-rich tissues such as tendons (Shepherd et al., 2014; Ganghoffer et al., 2016), skin (Pissarenko et al., 2019; Kang and Wu, 2011; Remache et al., 2018; Payne et al., 2015), bones (Abdel-Wahab et al., 2011; Novitskaya et al., 2014), heart valves (Anssari-Benam et al., 2011) etc. demonstrated viscoelastic responses. Moreover, collagen at molecular (Gautieri et al., 2012) and fibrillar (Shen et al., 2011; Gautieri et al., 2013) levels also exhibited a complex viscoelastic behaviour, attributed to various sliding mechanisms between molecules and fibrils/fibres (Gautieri et al., 2012). The creep behaviour of collagenous materials was generally characterised by primary and secondary creep (Bertassoni et al., 2016; Shen et al., 2011; Shepherd et al., 2014; Abdel-Wahab et al., 2011; Novitskaya et al., 2014) while the stress-relaxation was found to depend on the tissue hierarchy and other ground substances (Shen et al., 2011). From these experimental data, time-dependent properties are generally not extracted directly; instead, these data are usually fitted into viscoelastic models (e.g. the quasi-linear viscoelasticity (QLV) model, Maxwell-Weichert model or Prony series) to obtain the corresponding moduli and characteristic times. Despite several studies of the viscoelastic properties of collagenous tissues, there is limited work related to the time-dependent response of pure collagen films and determination of their associated moduli and relaxation times.

Part I of this work (Bose et al., 2020) demonstrates the importance of in-aqua testing conditions, mimicking the in-vivo environment for potential biomedical applications, which drastically changes the mechanical response of collagen. It was found that dry collagen had elasto-plastic behaviour with strain-hardening, while in-aqua-tested collagen demonstrated a hyperelastic behaviour with a significant nearly 2.5 -fold - increase in its strain at failure (as compared to dry specimens), compensated by a reduction in its mechanical strength (by more than 90\%). Still, studies related to collagen-based biological tissues such as ligaments, skins, tendons and bones demonstrated their more complex inelastic responses (Kang and Wu, 2011; Remache et al., 2018; Pissarenko et al., 2019; Su et al., 2008; Susilo et al., 2016) and time-dependent behaviour (Shepherd et al., 2014; Abdel-Wahab et al., 2011; Pissarenko et al., 2019; Remache et al., 2018). Hence, Part II of this work focuses on the inelastic and time-dependent response of collagen film in dry and hydrated or in-aqua conditions. It is divided into three parts: (a) evaluation of inelastic deformation and energy dissipation of collagen (uniaxial tensile cyclic tests dry and in-aqua); (b) assessment of frequency-dependent elastic and viscous responses of dry and hydrated collagen films; (c) investigation of the creep and stress-relaxation response of collagen under different stress and strain conditions, respectively, under ambient conditions. The normalised creep values (obtained from experiments) were used to estimate the Prony series coefficients in Abaqus Simulia.

\section{Materials and methods}

Collagen solutions $(8 \mathrm{mg} / \mathrm{ml})$ were prepared from bovine Achilles tendons (obtained from Sigma-Aldrich) using $0.05 \mathrm{M}$ acetic acid (purchased from Sigma-Aldrich) and stored at $2-6{ }^{\circ} \mathrm{C}$ for $48 \mathrm{~h}$. Next, the solutions were stirred for $4 \mathrm{~h}$ at $1500 \mathrm{rpm}$, maintaining a temperature of $2-6{ }^{\circ} \mathrm{C}$. The solutions were then subjected to centrifugation for $180 \mathrm{~s}$ at $2500 \mathrm{rpm}$ to remove the undissolved collagen, and then, degassed for $3 \mathrm{~h}$ to remove microbubbles. Lastly, the solution was poured in a polystyrene (PS) petri-dish and left in a fume hood for a couple of days to allow solvent evaporation. Fourier Transform Infrared Spectroscopy (FTIR) was used to identify the main functional groups of collagen before and after film formation (see Fig. 2, Bose et al., 2020 for details).

All mechanical testing (except DMA) were carried out using the Instron 5944 with a Bio-Puls Bath system (Instron 3130-100 Bio-Puls Bath, Instron, USA). The Bio-Puls system generated an environment suitable for in-vivo analysis of biomaterials. Dynamic mechanical analysis (DMA) was carried out with a Mettler Toledo DMA machine, using its tension mode. In this paper, collagen films tested at ambient conditions without being soaked in water are denoted as $\mathrm{Col}_{\mathrm{D}}$ samples, while specimens tested in-aqua are referred to as $\mathrm{Col}_{\mathrm{A}}$ samples (Table 1 ). In case of DMA, hydrated $\left(\mathrm{Col}_{\mathrm{H}}\right)$ samples were tested as the machine could not operate in a water bath. It is worth mentioning that no significant difference in the mechanical properties were observed between films tested in-aqua at room temperature (RT) and at physiological temperature $\left(37^{\circ} \mathrm{C}\right)$ in Part I. Thus, only RT was considered in this paper.

\subsection{Elasto-plastic behaviour}

The elasto-plastic behaviour of collagen films was investigated under different cyclic loading regimes and environmental conditions. Specimens $(n=5)$ with dimensions of $45.00 \mathrm{~mm} \times 5.00 \mathrm{~mm} \times 0.05 \mathrm{~mm}$ (same as of tensile samples in Part I) were subjected to loadingunloading cycles under two different environmental conditions (Table 1): (a) at ambient temperature and humidity ( $\mathrm{Col}_{\mathrm{D}}$ samples); (b) inside a bio-bath containing water $\left(\mathrm{Col}_{\mathrm{A}}\right.$ samples). The $\mathrm{Col}_{\mathrm{A}}$ collagen samples were pre-hydrated (in water) for $10 \mathrm{~min}$ before the loading and the increase in the thickness (approximately by $0.08 \mathrm{~mm}$ ) was noted. Two cyclic loading regimes were employed for $\mathrm{Col}_{\mathrm{D}}$ films were subjected: (i) incrementally increased load amplitude (nine cycles: starting at $5 \%$ of ultimate tensile strength (UTS) loading to $80 \%$ of UTS, with an increment of $10 \%$ of UTS loading from the second cycle; the UTS was 75 

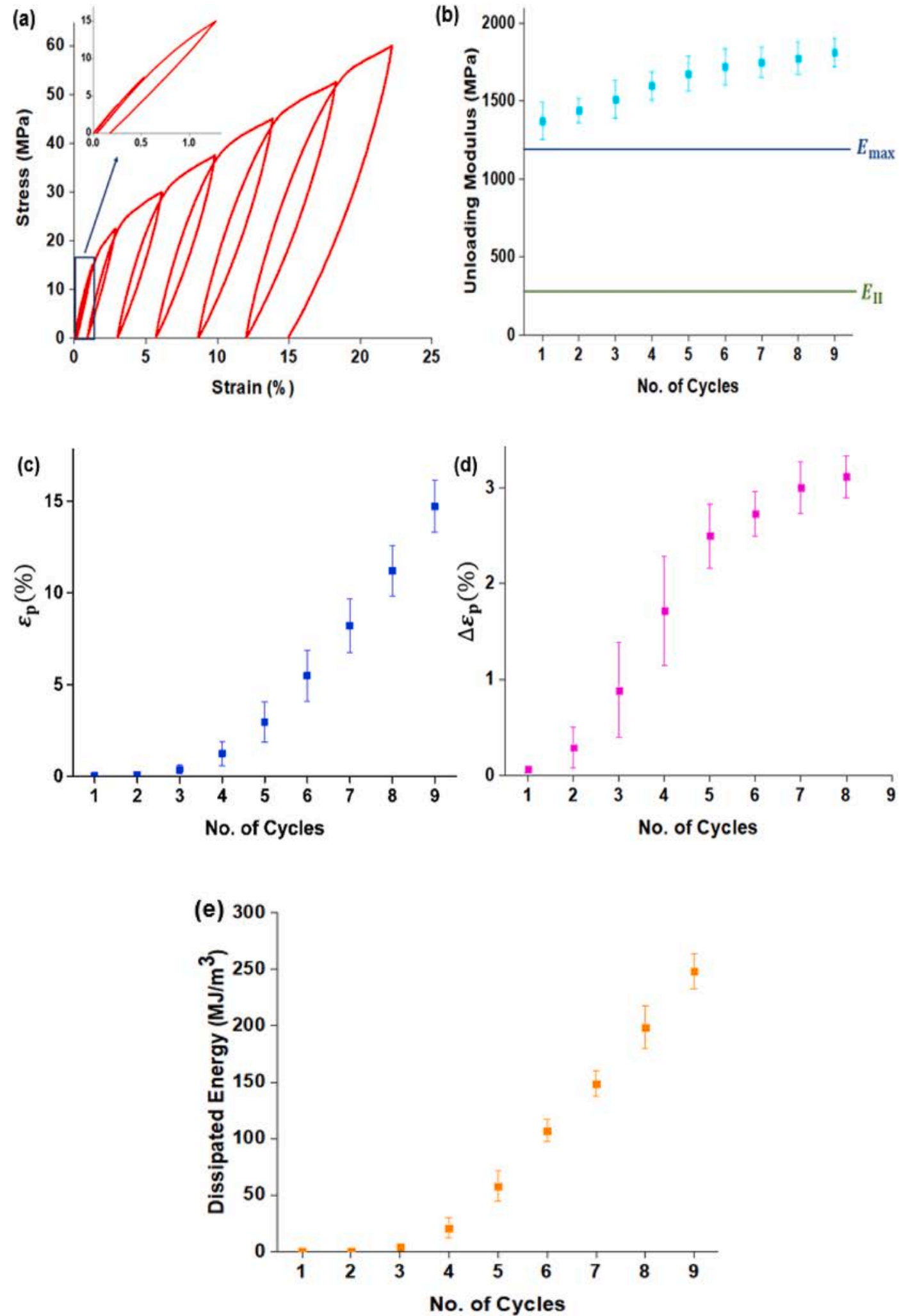

Fig. 1. (a) Stress-strain curve for incremental cyclic loading of in-air ( $\mathrm{Col}_{\mathrm{D}}$ ) specimens (inset showing first three cycles). Effect of number of cycles on unloading modulus (b), total plastic strain (c), change in plastic strain (d) and dissipated energy (e).

MPa from Part I of Col$_{\mathrm{D}}$ samples); (ii) constant amplitude (40 cycles at $5 \%, 20 \%$ and $30 \%$ of UTS, representing low, intermediate and high load levels, respectively). The samples neither failed after 9 cycles in the first regime loading nor after 40 cycles after second regime. $\mathrm{Col}_{\mathrm{A}}$ films were subjected to constant-amplitude cyclic loading for 20 cycles at $5 \%, 20 \%$ and $30 \%$ of UTS (the level of UTS was $2.74 \mathrm{MPa}$ for $\mathrm{Col}_{\mathrm{A}}$, see Part I), representing the low, intermediate and high stress levels. It is worth mentioning that none of the $\mathrm{Col}_{\mathrm{A}}$ samples failed during these tests, and the stabilization in energy dissipation was obtained within 20 cycles. All the tests were carried out at $0.001 \mathrm{~s}^{-1}$ strain rate (see Part I for test 

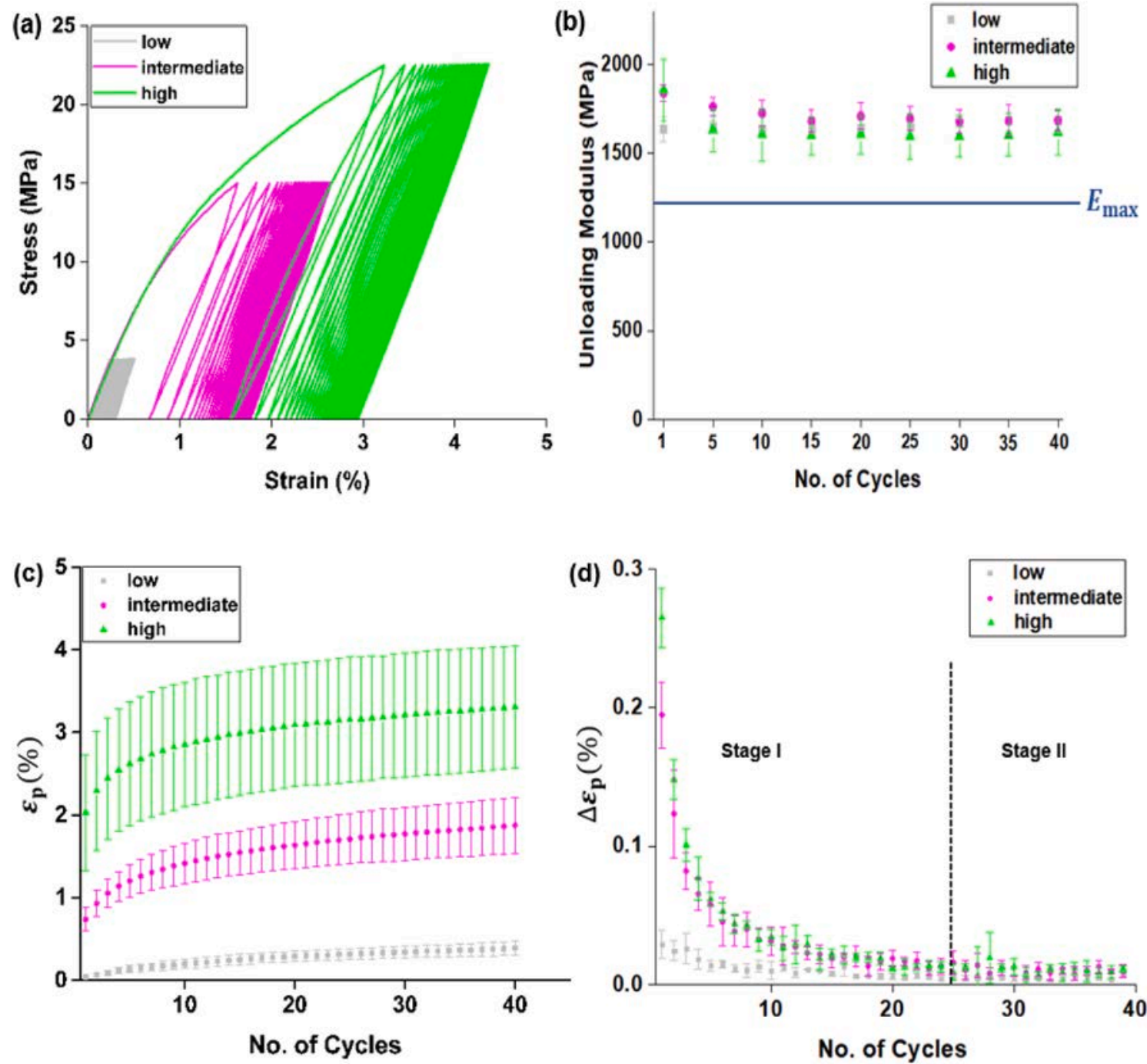

Fig. 2. (a) Stress-strain curves for monotonic cyclic loading for low, intermediate and high stress levels (5\%, 20\% and $30 \%$ of UTS, respectively). Effect of number of cycles on unloading modulus (b), total plastic strain (c) and change in plastic strain (d) for $\mathrm{Col}_{\mathrm{D}}$ specimens.

results on the effect of strain rate on collagen behaviour).

\subsection{Dynamic mechanical analysis}

The viscoelastic behaviour of collagen was quantified using DMA. This technique separates the viscous response from the elastic one upon application of sinusoidal oscillation, usually in a range of frequencies from which the material's time-dependent behaviour was quantified.

A frequency sweep in DMA was performed at RT on collagen films $(n=3)$ with dimensions $9.50 \mathrm{~mm} \times 4.00 \mathrm{~mm} \times 0.05 \mathrm{~mm}$ at constant strain. The force offset and amplitude were selected after conducting force sweeps for each sample to ensure accurate measurement of the modulus. The system was calibrated with a reference silicon bar sample with known material properties prior to the experiment. The tests were performed with $\mathrm{Col}_{\mathrm{D}}$ and $\mathrm{Col}_{\mathrm{H}}$ samples (Table 1). Hydrated specimens were used because the system does not operate in a water bath. It is worth mentioning that the dimensional changes $(9.50 \mathrm{~mm} \times 5.50 \mathrm{~mm} \times 0.08 \mathrm{~mm})$ for hydrated samples (pre-hydrated for $10 \mathrm{~min}$ ) were used for data extraction. The frequency sweep was performed in the range of $0.1 \mathrm{~Hz}-10 \mathrm{~Hz}$, which corresponds to the physiological frequency of normal human activities such as walking, running (Sweeney et al., 1965). This frequency range was earlier used to analyse DMA response of biomaterials such as chicken collagen (Oechsle et al., 2017), hydrogels (Kocen et al., 2017) etc.

\subsection{Creep and relaxation behaviours}

Creep and relaxation behaviours of the studied collagen films were tested at various stress and strain levels. Specimens $(n=3)$ with dimensions $45.00 \mathrm{~mm} \times 5.00 \mathrm{~mm} \times 0.05 \mathrm{~mm}$ (same as tensile samples in Part I) were subjected to both creep and stress-relaxation tests. For the former test, collagen films were subjected to $40 \%, 50 \%$ and $60 \%$ of UTS obtained from the tensile test; they correspond to $30 \mathrm{MPa}, 37.5 \mathrm{MPa}$ and $45 \mathrm{MPa}$, respectively. To estimate the creep exponent $(\eta)$ using the Norton's creep law, medium stress levels was needed (Abdel-Wahab et al., 2011). The stress was ramped to the desired values and was kept constant for $5400 \mathrm{~s}$. The corresponding deformation was recorded as displacement-time curves, used later to calculate the creep strain.

For stress relaxation, the extensions were ramped to deformation corresponding to tension stresses of 40,50 and $60 \%$ of UTS loading; they were $1.4 \mathrm{~mm}, 1.92 \mathrm{~mm}$ and $2.52 \mathrm{~mm}$, respectively. After this, the extension was constant for $5400 \mathrm{~s}$, while the decrease in the force amplitude was recorded over time. The force-time values were used to generate corresponding stress-relaxation curves.

The Abaqus commercial software (Abaqus Simulia 6.13) was used to characterise the viscoelastic parameters (moduli and characteristic 
times) of collagen by the relaxation modulus using the Prony series. The creep strain obtained from the experimental results was converted into the creep compliance using the following expression:

$j_{\mathrm{s}}(t)=\frac{\varepsilon(t)}{\sigma_{\mathrm{c}}}$,

where $\varepsilon(t)$ and $\sigma_{\mathrm{c}}$ are the strain at each time interval and the constant stress applied for the whole process, respectively. Normalised values of this compliances were used as an input for Abaqus software to obtain the corresponding dimensionless relaxation modulus and Prony-series parameters. The nominal stress-strain values (tensile data) were employed to describe the elastic behaviour of collagen, while normalised creep compliance was used in Abaqus as creep test data. The last value of normalised creep compliance was used as long-term modulus. Abaqus was then used to calculate the normalised dimensionless relaxation modulus $\left(e_{\mathrm{R}}(t)\right)$ and Prony-series parameters using the following relations:

$e_{\mathrm{R}}(t)=\frac{E_{\mathrm{R}}(t)}{E_{0}}$,

where $E_{\mathrm{R}}(t)$ is the relaxation modulus at time $t$ and $E_{0}$ is the instantaneous modulus, defined as:

$E_{\mathrm{R}}(t)=\frac{\sigma(t)}{\varepsilon}$,

$E_{0}=E_{\mathrm{R}}(0)$.

The dimensionless relaxation expression has the limits of $e_{\mathrm{R}}(0)=1$ and $e_{\mathrm{R}}(\infty)=\frac{E_{\infty}}{E_{0}}$ and is defined by the Prony series expansion in the following way:

$e_{\mathrm{R}}(t)=1-\sum_{i=1}^{N} e_{i}\left(1-e^{-t / \tau_{i}}\right)$

where $e_{i}$ and $\tau_{i}$ are the material constants and $i=1, \ldots N$.

All the experimental results were statistically analysed using at least five specimens (for cyclic tests) and at least three specimens (for DMA, creep and stress-relaxation tests; this number was considered sufficient due to high reproducibility of results, with $R^{2}>0.95$ ) and is reported as mean \pm standard deviation (S.D.).

\section{Results and discussions}

\subsection{Elasto-plastic behaviour}

\subsubsection{Incremental cyclic loading (in air)}

The tested collagen films $\left(\mathrm{Col}_{\mathrm{D}}\right)$ demonstrated non-linear elasticplastic behaviour for all the stress levels (nine cycles) in incremental cyclic loading. Typical stress-strain curves obtained for loadingunloading cycles are depicted in Fig. 1a, which revealed an increasing plastic deformation throughout the entire process. The inset (Fig. 1a) shows the presence of plastic deformation in collagen even at the lowest levels of stresses (first three cycles). The unloading modulus was calculated for each cycle to exclude the effect of plasticity; and an increase in the average modulus from the 1 st to 9 th cycle of $32 \%$ (from $1373 \pm 118.5 \mathrm{MPa}$ to $1812 \pm 94.5 \mathrm{MPa}$ ) was observed (Fig. 1b), demonstrating a hardening behaviour. The unloading modulus was much higher than the $E_{\max }$ and $E_{\mathrm{II}}(1172 \pm 193.3 \mathrm{MPa}$ and $273.5 \pm 33.1$ $\mathrm{MPa}$, respectively, obtained in Part I) for monotonous tension. This further denoted the effect of plastic behaviour through the entire deformation phase.

The plastic strain $\varepsilon_{\mathrm{p}}$ and change in plastic strain $\Delta \varepsilon_{\mathrm{p}}$ were extracted from the cyclic curves and plotted with corresponding error bars in Fig. 1 $\mathrm{c}$ and d, respectively. The latter parameter was calculated using the following relation:
$\Delta \varepsilon_{\mathrm{p}}(\%)=\left(\varepsilon_{\mathrm{n}+1}-\varepsilon_{\mathrm{n}}\right) \times 100$

where $\varepsilon_{\mathrm{n}}$ is the strain at $n^{\text {th }}$ cycle.

The growing plastic deformation (as obtained from $\varepsilon_{\mathrm{p}}$ and $\Delta \varepsilon_{\mathrm{p}}$ ) was also observed in other collagenous tissues such as bone (Dong et al., 2013) and mouse skin (Muñoz et al., 2008), subjected to progressive loading cycles. A strong effect of the progressive cyclic loading regime on accumulation of plastic deformation is apparent from Fig. 1 (c): initially very slow, the process accelerates, becoming a nearly linear one. This results in a typical sigmoidal curve for plastic strain increment (Fig. 1d), effectively reaching a plateau at the end of the test.

A hysteresis loss or dissipated energy was also assessed for the collagen film under progressive loading (Fig. 1e). It is the amount of energy dissipated during each loading-unloading cycle of deformation and obtained by integrating the area between loading-unloading curves. At lower stress levels (for first two cycles) the energy loss was rather very small at $0.037 \mathrm{MJ} / \mathrm{m}^{3}$ (1st cycle) and $0.384 \mathrm{MJ} / \mathrm{m}^{3}$ (2nd cycle), but increased to $248 \mathrm{MJ} / \mathrm{m}^{3}$ for the last (9th) cycle signifying a more viscous behaviour at higher stress levels.

\subsubsection{Constant-amplitude cyclic test}

3.1.2.1. In-air cyclic test. Specimens of the collagen film ( $\left.\mathrm{Col}_{\mathrm{D}}\right)$ were subjected to forty cycles with constant levels of load-amplitude $5 \%, 20 \%$ and $30 \%$ of UTS, corresponding to low- (3.75 MPa), intermediate- (15 $\mathrm{MPa}$ ) and high-stress (22.5 MPa) regimes, respectively (Fig. 2a). The non-linear plastic deformation was observed across all the stress regimes. The maximum increase in deformation occurred in the first cycles for all the stress levels; it decreased gradually with continuing mechanical cycling. The unloading modulus (Fig. 2b) for the low stress level did not exhibit any specific trend, so it is insensitive to mechanical cycling. However, for intermediate and high stress levels, this modulus decreased (by $12 \%$ for the 5 th cycle for the high-stress regime) after the first cycle, becoming later insensitive to increase in mechanical cycling. The almost constant modulus during this process suggests that the dissipation process was not accompanied by damage accumulation or stress softening (Liu et al., 2018). Still for all the loading conditions, the unloading modulus exceeded $E_{\max }$ (see Part I), a further demonstration of stiffening as a result of plastic deformation.

The levels of plastic strain and its incremental change $\Delta \varepsilon_{\mathrm{p}}$ were calculated for different stress levels (Fig. $2 c$ and d, respectively). The accumulation of plastic strain increased with the growing number of cycles (Fig. 2c). This behaviour can be referred to as ratchetting, commonly found in metals (Kang and Liu, 2008; Kang, 2008). Kang and $\mathrm{Wu}$ (2011) and Gao et al. (2015) also observed the ratchetting behaviour in collagen-rich tissues such as porcine skin and articular cartilage, respectively, during cyclic loadings. The ratchetting strain in collagen films exhibited their visco-elastic and plastic properties (Kang and Wu, 2011). The evolution of incremental plastic strain in cyclic loading (Fig. 2d) can be divided into two characteristic stages: Stage I- initial large plastic deformation in collagen due to recruitment or sliding mechanism of the fibrils; Stage II- plastic deformation reached the saturation, with predominantly viscoelastic response of the collagen material, within each cycle.

Apparently, accumulation of plastic strain with increase in the stress levels (Fig. 2c) was also observed in other collagen-based biological tissues (Kang and Wu, 2011). However, after 25 mechanical cycles, the values of the strain increments for all the stress levels were very close, confirming gradual stabilization of plastic deformation and damage.

Based on these observations, two distinct deformation mechanisms in the cyclically loaded collagen film may be highlighted: (i) the elastic response attributed to load-bearing capacity of collagen fibrils and fibres, found throughout the entire deformation stages; (ii) the irreversible plastic and damage responses linked to the initial intra-fibril/fibre sliding and matrix debonding, presented only during the initial loading. 

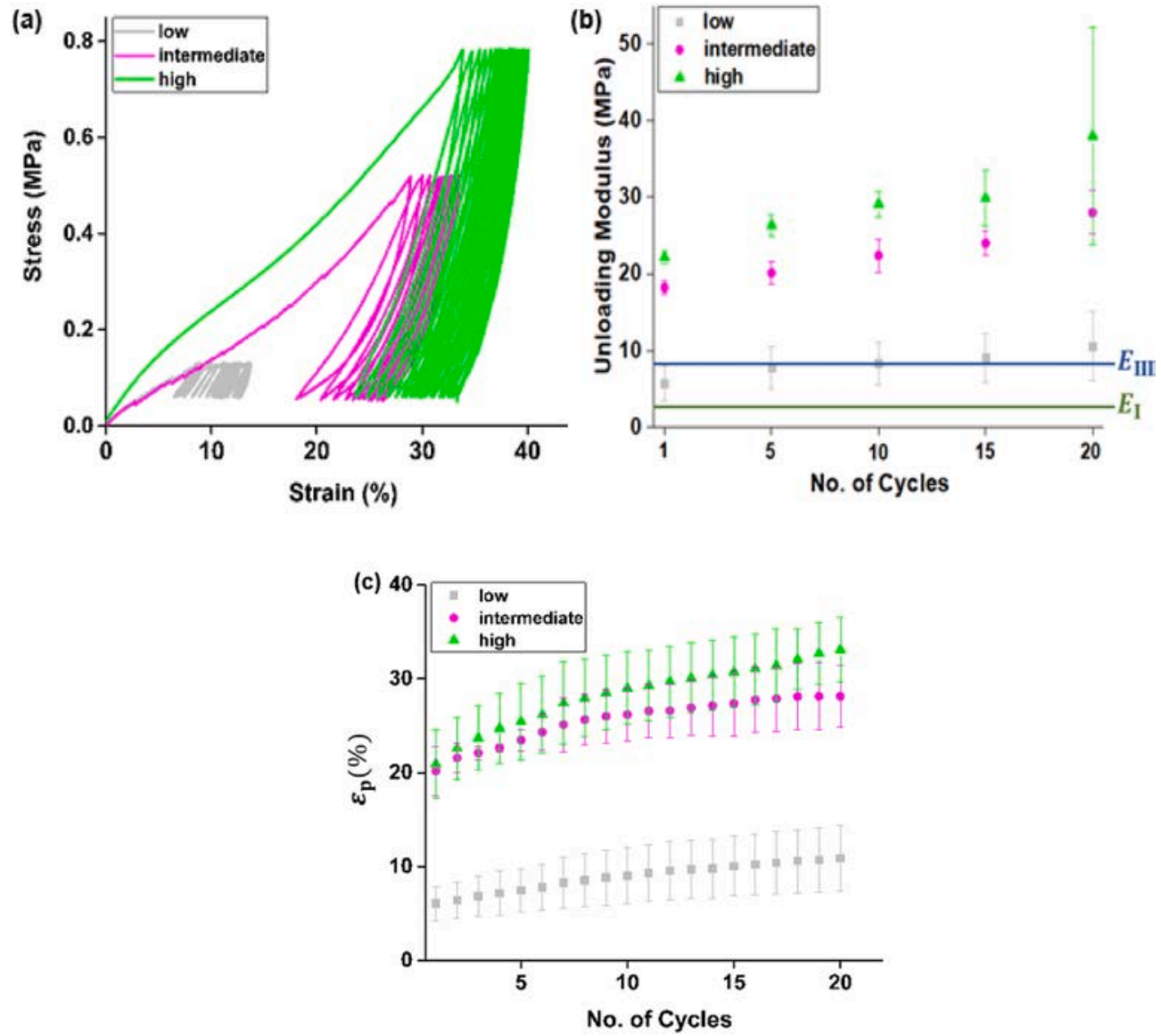

Fig. 3. (a) Stress-strain curves for monotonic cyclic loading for low, intermediate and high stress levels ( $5 \%, 20 \%$ and $30 \%$ of UTS, respectively). Effect of number of cycles unloading modulus (b) and residual strain (c) for $\mathrm{Col}_{\mathrm{A}}$ specimens.

3.1.2.2. In-aqua cyclic test. Pre-hydrated specimens (in water for 10 $\mathrm{min})$ of the collagen film $\left(\mathrm{Col}_{\mathrm{A}}\right)$ were loaded in-aqua with constantamplitude cycles (20 cycles at $5 \% .20 \%$ and $30 \%$ of UTS, corresponding to low-, intermediate- and high-stress regimes, respectively) in order to investigate the effect of water on elastic-plastic behaviour of collagen. None of the tested samples failed within 20 cycles of mechanical loading in all stress regimes. For in-aqua tests, the unloading was performed down to $0.5 \mathrm{MPa}$ to avoid buckling of the samples as a result of excessive deformation in water. The collagen exhibited completely different nonlinear response in-aqua (compared to that of $\mathrm{Col}_{\mathrm{D}}$ ) (Fig. 3a). It behaved more like a hyperelastic material. Still, the maximum plastic deformation occurred in the first cycle. Its level increased with the increase in the stress levels, showing some signs of saturation. The unloading modulus exhibited a stiffening behaviour with the increase in the number of cycles (Fig. 3b) (see also Susilo et al., 2016; Su et al., 2008), in contrast to the findings observed in $\mathrm{Col}_{\mathrm{D}}$ (Fig. 2b), with nearly constant modulus. An increase of more than $50 \%$ in the modulus was observed for all level of stress tests: for low- $5.7 \mathrm{MPa}-10.5 \mathrm{MPa}$; for intermediate- $18 \mathrm{MPa}-28$ MPa; for high- $22 \mathrm{MPa}-38 \mathrm{MPa}$. This stiffening behaviour (referred to as cyclic stiffening) of collagen in-aqua conditions can be attributed to the reorientation or realignment of collagen fibrils along the loading direction (Susilo et al., 2016). The elastic moduli ( $E_{\mathrm{I}}$ and $E_{\text {III }}$ ), obtained for the characteristic stages in quasi-static tests (in Part I of this paper), are also presented in Fig. 3b, demonstrating the effect of this stiffening.

The level of plastic strain caused by in-aqua mechanical cycling was more than an order of magnitude higher than that in the in-air tests. It also exhibited a ratcheting behaviour (Fig. 3c), similar in earlier reported for collagenous tissues such as porcine skin (Kang and Wu, 2011) and articular cartilage (Gao et al., 2015). It was suggested that water could acted as plasticizing agent in collagenous material to allow large-scale deformation for in-aqua conditions (Yuan and Verma, 2006).

\subsubsection{Comparison between in-air and in-aqua tests}

3.1.2.3.1. Hysteresis loss. The levels of hysteresis loss for a constant amplitude of cycling $\mathrm{Col}_{\mathrm{D}}$ and $\mathrm{Col}_{\mathrm{A}}$ were compared for each cycle and all stress regimes (Fig. 4). In all three loading regimes, the maximum energy dissipation was always observed in the first cycle for both $\mathrm{Col}_{\mathrm{D}}$ and $\mathrm{Col}_{\mathrm{A}}$ specimens, following gradual decrease as the number of cycles increased.

In the low stress regime (Fig. 4a), the energy dissipation dropped significantly after the first cycle for $\mathrm{Col}_{\mathrm{A}}$ ( $87 \%$ from the 1st to the 2nd cycle), while this drop was less significant for $\mathrm{Col}_{\mathrm{D}}$ specimens $(27 \%)$. Moreover, the energy dissipation was higher for $\mathrm{Col}_{A}$ compared to $\mathrm{Col}_{\mathrm{D}}$ throughout most of the process. The opposite was observed for both intermediate (Fig. 4b) and high (Fig. 4c) stress levels: the hysteresis loss for $\mathrm{Col}_{\mathrm{D}}$ specimens was higher throughout.

These findings suggested that behaviour of $\mathrm{Col}_{\mathrm{D}}$ was less viscous at low stress regimes; this changed at intermediate and high stresses. For both environments and all three stress levels a gradual stabilization of energy dissipated per cycle was achieved at the end of the tests.

3.1.2.3.2. Unloading modulus. The unloading modulus was calculated for each of the recovery curves extracted from the cyclic stressstrain graphs and both the normalised and absolute unloading modulus were plotted as function of a number of cycles (Fig. 5). The normalised unloading modulus exhibited contrasting trends: decreasing for $\mathrm{Col}_{\mathrm{D}}$ and increasing for $\mathrm{Col}_{\mathrm{A}}$ (Fig. 5a, c, e). Apparently, $\mathrm{Col}_{\mathrm{D}}$ specimens were nearly insensitive to mechanical cycling at low (Fig. 5a) stress level, while $\mathrm{Col}_{\mathrm{A}}$ specimens demonstrated cyclic stiffening. In case of intermediate (Fig. 5c) and high (Fig. 5e) stresses, the unloading modulus of $\mathrm{Col}_{\mathrm{D}}$ specimen was higher for the first cycle, becoming 

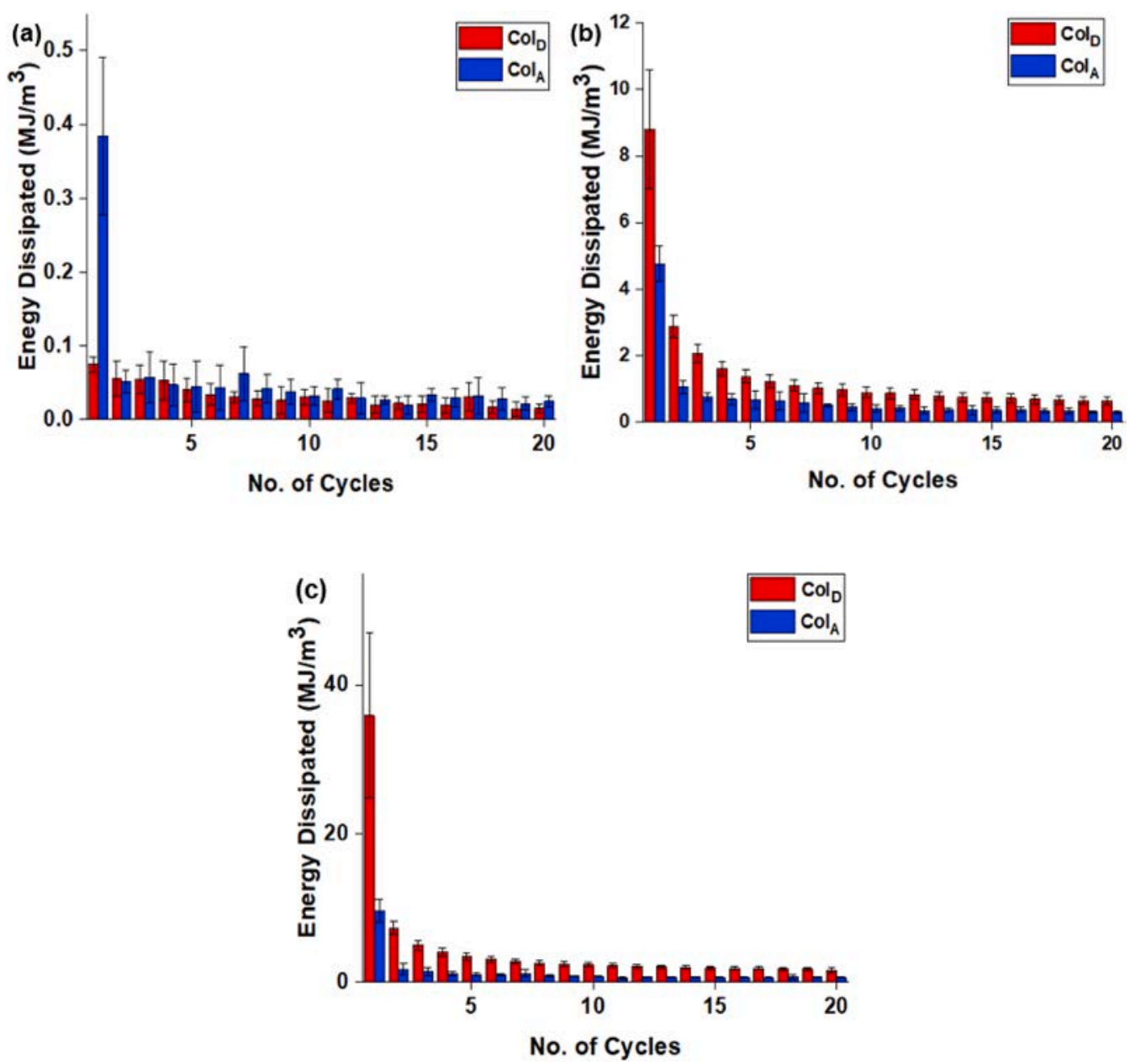

Fig. 4. Energy dissipation (or hysteresis loss) for low (a), intermediate (b) and high (c) levels of stress, corresponding to $5 \%$, $20 \%$ and $30 \%$ UTS, respectively, for different environments $\left(\mathrm{Col}_{\mathrm{D}}-\right.$ in air and $\mathrm{Col}_{\mathrm{A}}-$ in aqua).

effectively insensitive to subsequent mechanical cycling. This provides strong evidence that collagen did not exhibit damage accumulation or softening after the first cycling (Liu et al., 2018). However, for $\mathrm{Col}_{\mathrm{A}}$, cyclic stiffening was observed for both intermediate and high stress levels (Fig. $5 c$ and e, respectively). For all the levels of stresses, the unloading modulus of $\mathrm{Col}_{\mathrm{D}}$ was about two-orders of magnitude higher if compared to $\mathrm{Col}_{\mathrm{A}}$ (Fig. 5b, d, f).

3.1.2.3.3. Residual strain. Residual strain represents the permanent deformation occurred for each cycle after the unloading process; its magnitudes were extracted for both $\mathrm{Col}_{\mathrm{D}}$ and $\mathrm{Col}_{\mathrm{A}}$ specimens for three used stress level. For comparability, these magnitudes were normalised with the level of strain attained after the first cycle (Fig. 6).

For all the stress levels and in both the environmental conditions, collagen depicted the ratchetting strain, previously reported in collagenrich tissues such as porcine skin (Kang and Wu, 2011) and articular cartilage (Gao et al., 2015). At low stresses, the $\mathrm{Col}_{\mathrm{A}}$ specimen exhibited significantly quicker strain accumulation than $\mathrm{Col}_{\mathrm{D}}$ specimen (Fig. 6a). This difference reduced in the case of intermediate stress (Fig. 6b) effectively vanishing at high stress (Fig. 6c).

The upcoming section deals with the inelastic deformation of the collagen in-air and in-aqua conditions. Still, its long-term viscous timedependent behaviour should also be assessed. Thus, in the following section, two approaches are used to determine the time-dependent response of the studied collagen film: (i) Dynamic Mechanical Analysis; (ii) creep and stress-relaxation tests.

\subsection{Dynamic mechanical analysis: frequency sweep measurements}

Rheological properties of polymers can be estimated in both solid samples and in melts. In this study, three different viscoelastic properties of the collagen in dry and hydrated/wet states were measured: storage modulus $\left(E^{\prime}\right)$, loss modulus $\left(E^{\prime \prime}\right)$ and tan delta $(\delta)$. Average curves with corresponding error bars depicting $E, E^{\prime \prime}$ and $\tan \delta$ are plotted in Fig. 7 for the collagen film in dry and hydrated/wet state.

The storage modulus $\left(E^{\prime}\right)$ represents the material's ability to store energy elastically. It was observed that it increased with the increase in the frequency for both $\mathrm{Col}_{\mathrm{D}}$ and $\mathrm{Col}_{\mathrm{H}}$ (wet) specimens (Fig. 7a), similar to other reported collagenous tissues such as mitral valve (Wilcox et al., 2014), stratum corneum of porcine (Yuan and Verma, 2006), bovine cornea (Hatami-Marbini and Rahimi, 2015) etc. The increase in the level of $E^{\prime}$ may be attributed to shorter time intervals for the collagen fibrils to relax with increase in frequency. The magnitude of $E^{\prime}$ measured for $\mathrm{Col}_{\mathrm{D}}$ and $\mathrm{Col}_{\mathrm{H}}$ differed drastically, by three order of magnitude; such a considerable change in the quasi-static modulus was also observed in the tensile tests of $\operatorname{Col}_{\mathrm{D}}\left(E_{\max }=1172 \pm 193.3 \mathrm{MPa}\right.$ and $\left.E_{\mathrm{II}}=273.5 \pm 33.1 \mathrm{MPa}\right)$ and $\mathrm{Col}_{\mathrm{H}}$ $\left(E_{\mathrm{I}}=2.88 \pm 0.74 \mathrm{MPa}\right.$ and $E_{\mathrm{III}}=13.7 \pm 1.72 \mathrm{MPa}$ ) collagen films (see Part I). Similar difference in the storage modulus was reported for wet stratum corneum as compared of dry ones (Yuan and Verma, 2006) and explained by disruption of interfibrillar bonds.

The loss modulus $\left(E^{\prime \prime}\right)$ is linked to the viscous response and the ability of a material to dissipate energy. $E$ " obtained for $\mathrm{Col}_{\mathrm{D}}$ and $\mathrm{Col}_{\mathrm{H}}$ differed by two orders of magnitude (Fig. $7 \mathrm{~b}$ ). Moreover, the trend observed in $\mathrm{Col}_{\mathrm{H}}$ was very different from that in $\mathrm{Col}_{\mathrm{D}}$. $E$ " decreased for 

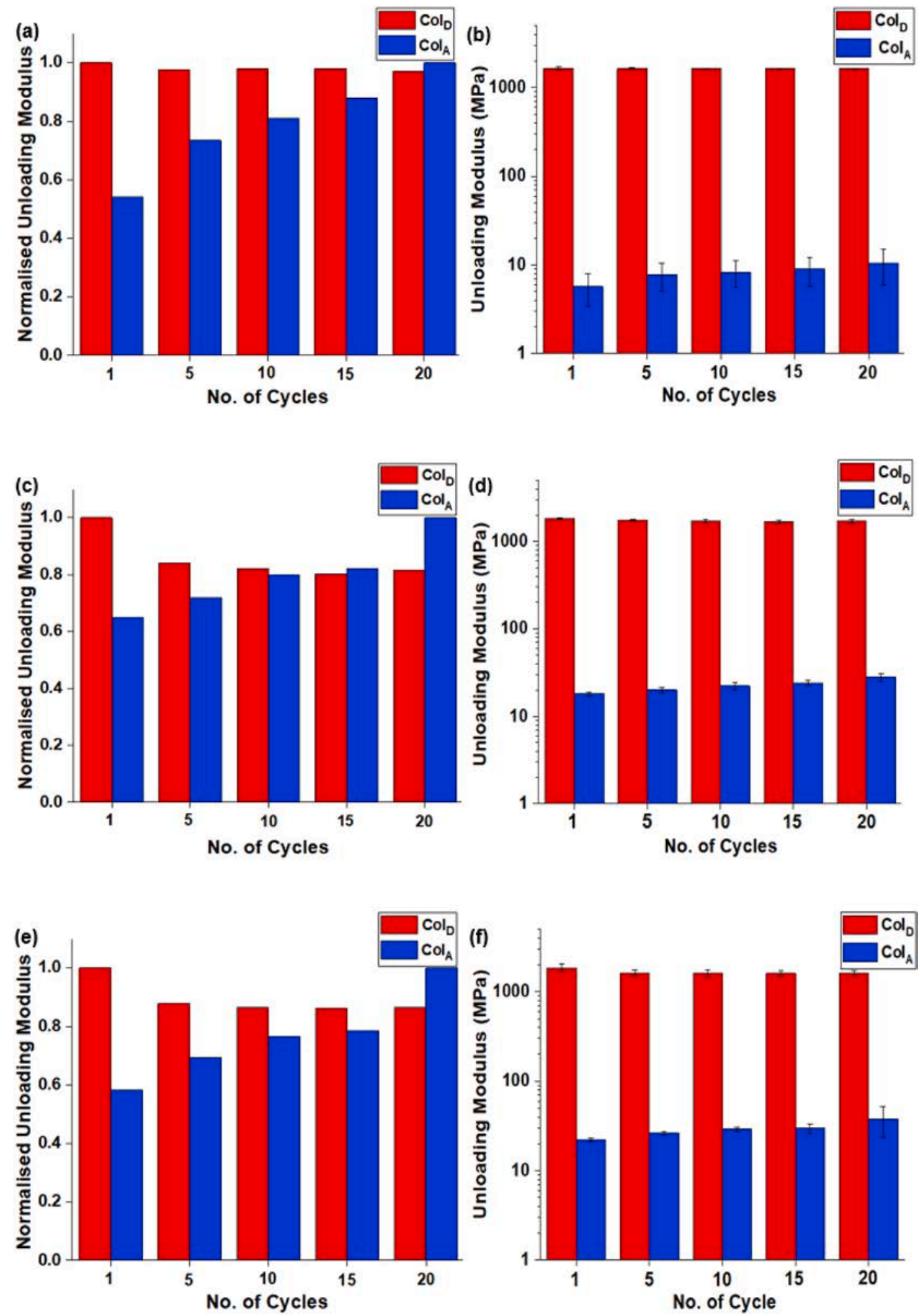

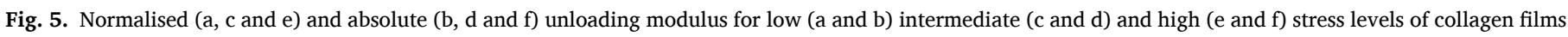
subjected to in-air $\left(\mathrm{Col}_{\mathrm{D}}\right)$ and in-aqua $\left(\mathrm{Col}_{\mathrm{A}}\right)$ conditions.

the latter with the increase in the frequency, denoting a diminished viscous response due to restricted movement of the polymeric chains, which decreased interfacial dissipation (Abdo et al., 2019; Rath et al.,

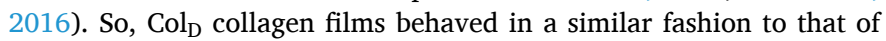
reinforced polymeric materials (Abdo et al., 2019; Venugopal et al., 2016; Rath et al., 2016). However, the hydrated collagen film depicted a response more predominant in soft materials such as hydrogels (Yang et al., 2012a; Ibrahim et al., 2011; Kocen et al., 2017) and collagenous tissues (Hatami-Marbini and Rahimi, 2015; Oechsle et al., 2017). With the increase in frequency, it exhibited an initial decrease in $E$ " due to lower relaxation time of collagen fibrils. Whereas, the subsequent increase in $E$ " with the increase in frequency may be attributed to the 

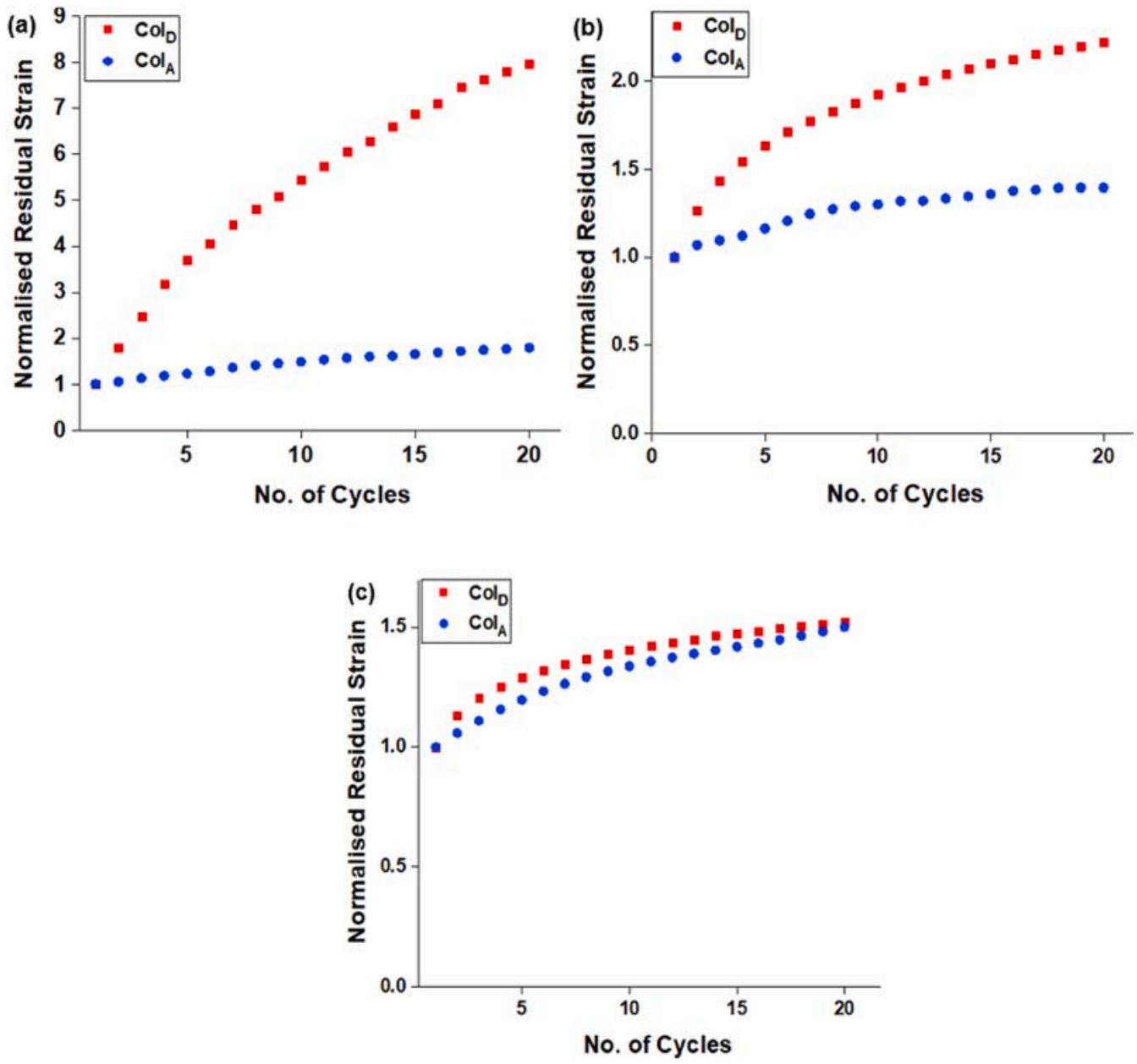

Fig. 6. Effect of cyclic loading on normalised residual strain for low (a) intermediate (b) and high (c) stress levels for collagen films subjected to in-air (Col ${ }_{D}$ ) and inaqua $\left(\mathrm{Col}_{\mathrm{A}}\right)$ conditions.

presence of water molecules, acting as plasticizer disrupting the interfibrillar bonds (Yuan and Verma, 2006).

Tan delta $(\delta)$ or loss tangent, is the ratio of the loss modulus to the storage one; it characterises the damping capability of the material and its ability to dissipate energy. It is also referred to as damping coefficient and describes the time shift between an applied cyclic force and transmitted resultant force.

Tan $\delta$ values greater than 1 represent prominent liquid-like behaviour (viscous behaviour) while values less than 1 denote solid-like behaviour (elastic behaviour) (de Vries et al., 2017). The obtained values of $\tan \delta$ for $\mathrm{Col}_{\mathrm{D}}$ and $\mathrm{Col}_{\mathrm{H}}$ were significantly lower than 1 (Fig. 7c), suggesting a solid-like behaviour of the collagen film. The hydrated specimens showed greater $\tan \delta$ values as compared to dry ones throughout the used frequency range (Fig. 7c). Its magnitude for $\mathrm{Col}_{\mathrm{D}}$ collagen film varied between 0.05 and 0.075 , with a decreasing trend, revealing a slightly lower contribution of viscosity at higher frequencies. A striking difference was observed in $\mathrm{Col}_{\mathrm{H}}$ where the $\tan \delta$ varied in the range of $0.12-0.24$, with an initial decrease followed by an increase.

Higher $\tan \delta$ values represent more viscous behaviour; thus, the presence of water molecules in the $\mathrm{Col}_{\mathrm{H}}$ samples affected the interfibrillar bonds, leading to a ductile response. $\mathrm{Col}_{\mathrm{D}}$ samples exhibited higher elastic properties and behaved more like solid polymeric materials (Rath et al., 2016; Abdel-Wahab et al., 2011). On the contrary, the $\mathrm{Col}_{\mathrm{H}}$ films depicted more viscous behaviour with $\tan \delta$ values comparable to those of other wet collagenous materials like wet stratum corneum (Yuan and Verma, 2006) and wet bone (Pathak et al., 2011). The obtained $\tan \delta$ values were well within the respective ranges - values $0.028-0.1$ and $0.12-0.25$ - reported for other dry and wet collagenous materials such as cornea, bone and femora (Table 2), confirming the results obtained in this study.

An Ashby chart (Ashby, 2011) was used to compare mechanical properties (damping coefficient and tensile strength) of non-metallic engineering materials with those for pure collagen films in dry and wet conditions obtained in this study (Fig. 8). Apparently, the properties of dry collagen were in the range previously reported for collagen (yellow domain in Fig. 8) in CES Granta (Edupack, 2019), within the subset of biological materials. However, the wet collagen exhibited the mechanical behaviour outside the domain for collagen but rather close to that of soft biological materials, elastomers and foams. Hence, it would be preferable to characterise the mechanical response of collagen in conditions which wholly or partially mimic in-vivo environment.

\subsection{Creep and stress-relaxation behaviour}

Viscosity of collagen should also affect its long-term performance. To assess it, creep and relaxation tests were performed. In the former, collagen specimens were subjected to three different stress levels of 30 $\mathrm{MPa}, 37.5 \mathrm{MPa}$ and $45 \mathrm{MPa}$ (corresponding to $40 \%, 50 \%$ and $60 \% \mathrm{UTS}$, respectively) for $5400 \mathrm{~s}$. An averaged creep response with respective data scatter was obtained at different loading conditions and presented in Fig. 9a. It was observed that in the initial few seconds the stress ramped to the desired amplitude, after which the deformation continued at a constant stress level. All the creep curves (Fig. 9a) have a similar 

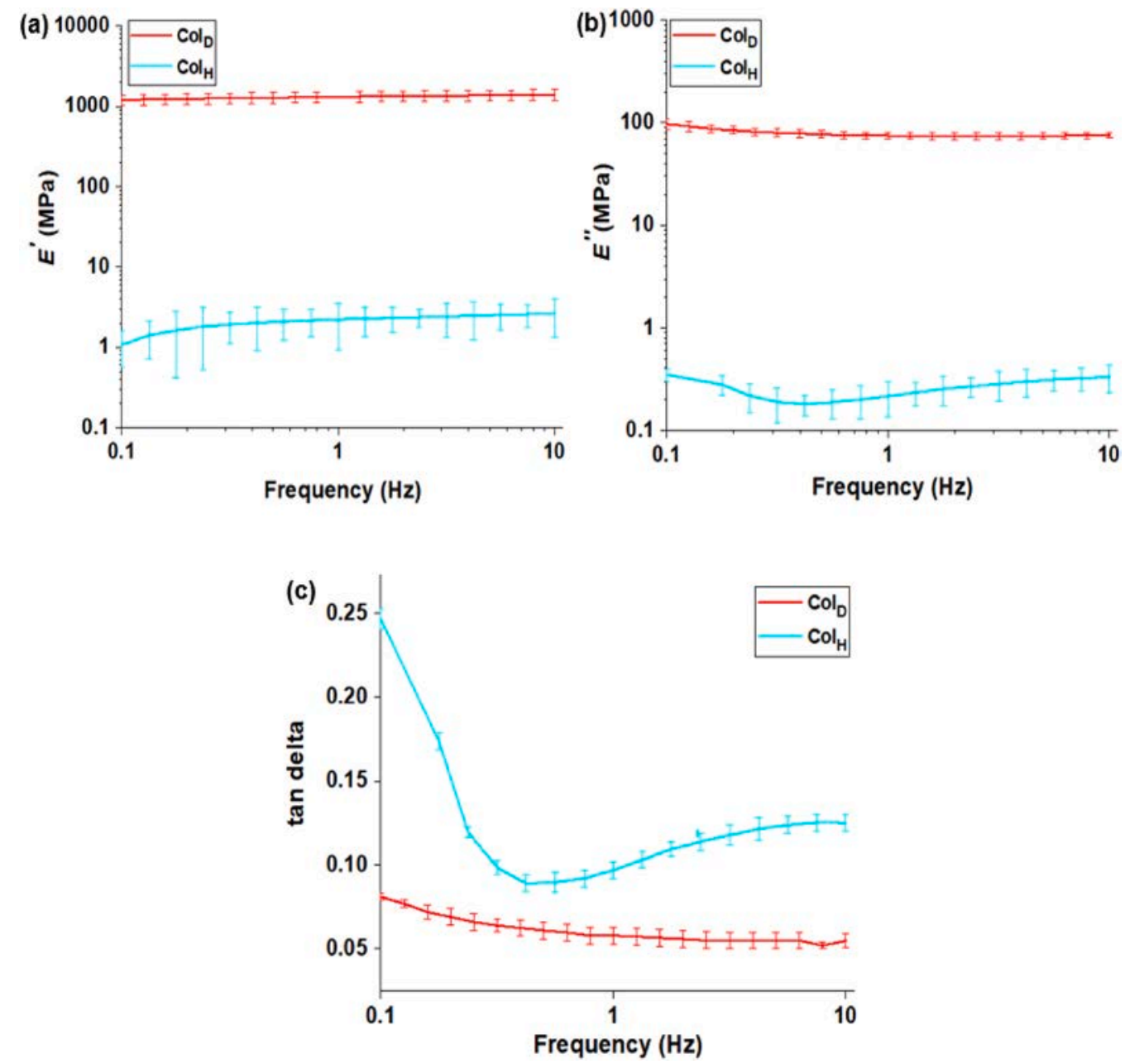

Fig. 7. Effect of frequency on storage modulus (a), loss modulus (b) and tan delta (c) for dry $\left(\mathrm{Col}_{\mathrm{D}}\right)$ and hydrated $\left(\mathrm{Col}_{\mathrm{H}}\right)$ collagen films.

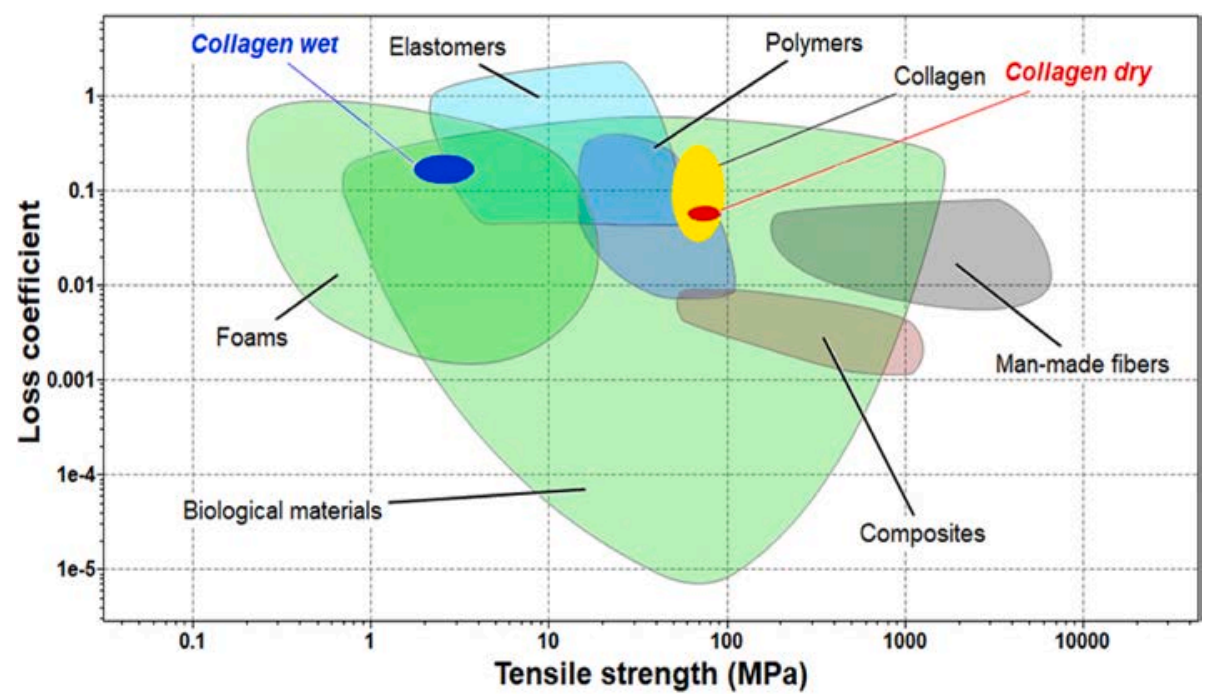

Fig. 8. Asbhy chart for loss coefficient plotted against tensile strength. The highlighted red and blue domains denote the mechanical properties of collagen tested in dry and wet conditions in this study. (For interpretation of the references to colour in this figure legend, the reader is referred to the Web version of this article.)

trend, with increasing strain levels for higher stresses applied. The initial rapid strain growth (till about $3000 \mathrm{~s}$ ) was followed by a much slower secondary creep for all the stress levels. A nearly constant magnitude of calculated strain rate was used to determine the end of the primary creep stage. The presence of primary and secondary creep regimes was previously reported in collagenous materials such as dentin (Bertassoni et al., 2016), collagen fibrils (Shen et al., 2011), tendons (Shepherd et al., 2014) and bones (Abdel-Wahab et al., 2011; Novitskaya et al., 

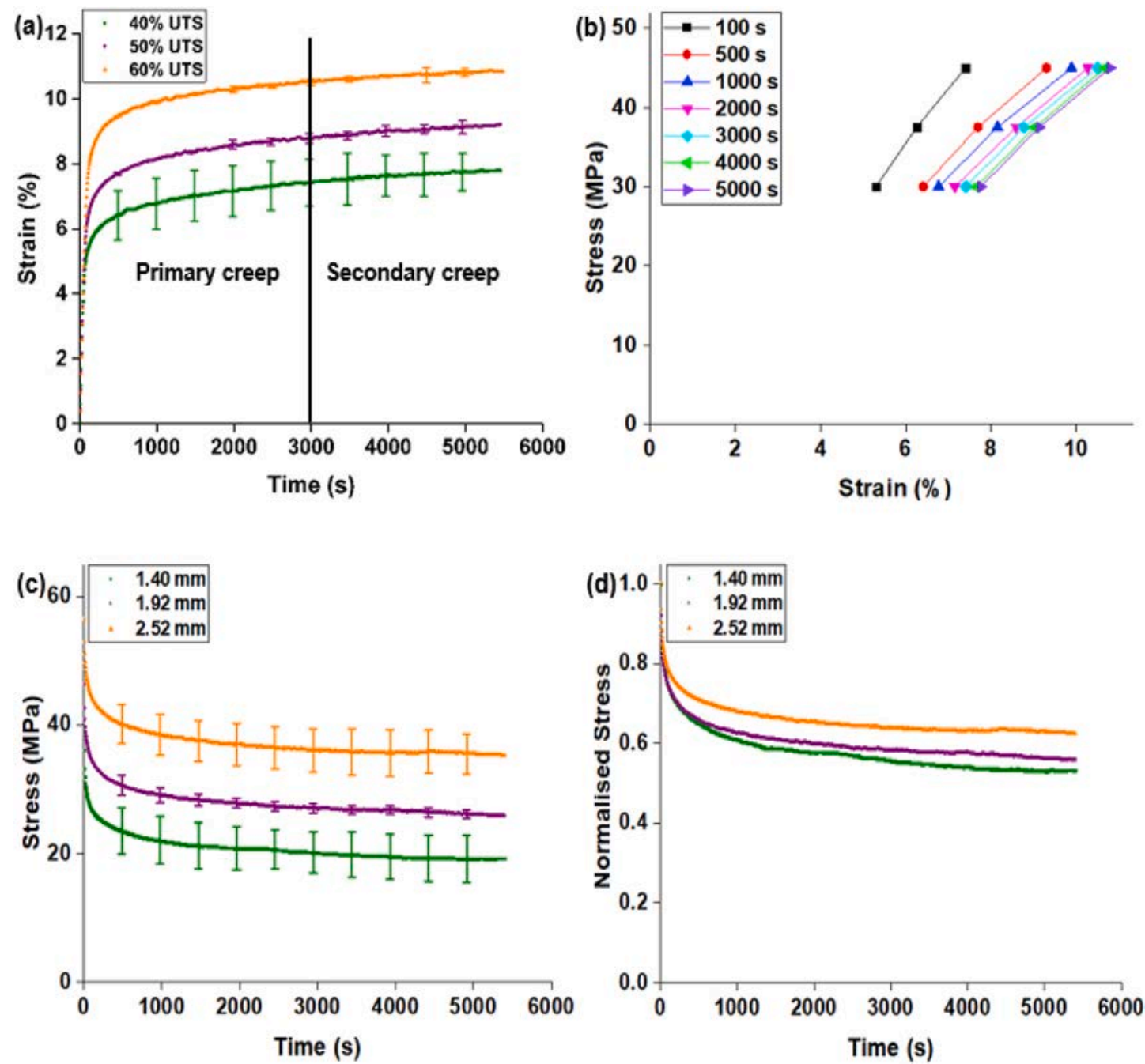

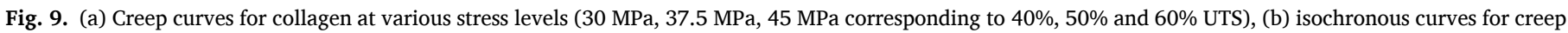

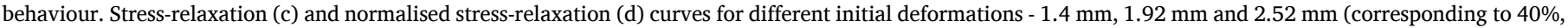
$50 \%$ and $60 \%$ UTS).

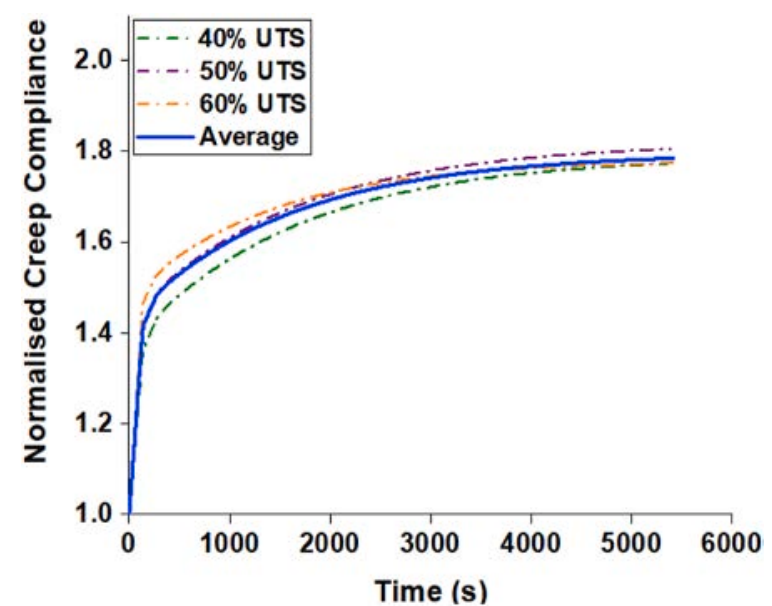

Fig. 10. Normalised creep compliance curves obtained from experiments for $40 \%, 50 \%$ and $60 \%$ UTS (dotted lines) and fitted curve from Abaqus results with single set of Prony-series parameters (blue line). (For interpretation of the references to colour in this figure legend, the reader is referred to the Web version of this article.)
2014).

As well known, creep curves can be also used to estimate whether the material's viscoelastic behaviour exhibits linear scaling (Wineman and Rajagopal, 2000): in such a case, creep function $J$ is proportional to the stress $-j(\sigma, t)=\sigma j(t)$. One way to study this is to consider the isochronous curves. Based on these curves (Fig. 9b), apparently, the studied collagen film depicted an almost linear viscoelastic response up to $60 \%$ of UTS.

A creep exponent $(\eta)$ was estimated using the Norton's creep law for the secondary creep rate (for medium stress level) as follows:

$\dot{\varepsilon}_{\mathrm{S}}=A(T) \sigma^{\eta}$

where $\dot{\varepsilon}_{\mathrm{S}}$ is the secondary creep-rate, $A(T)$ is the material parameter depending on the temperature $T$, and $\sigma$ is the applied stress. The average values of parameters $A=1.2 \times 10^{-13} \mathrm{MPa}^{-\eta} \mathrm{s}^{-1}$ and $\eta=4.85$ were obtained by determining the intersect and slope of the graph plotted for the secondary creep rate against the applied stress in the double logarithmic scale.

The non-linear stress-relaxation response with time for three different levels of initial deformation $-1.40 \mathrm{~mm}, 1.92 \mathrm{~mm}$ and $2.52 \mathrm{~mm}$, corresponding to $40 \%, 50 \%$ and $60 \%$ UTS, at $36 \mathrm{MPa}, 46 \mathrm{MPa}$ and 56 MPa, respectively - was obtained (Fig. 9c).

In all the cases, the stress relaxation followed the same trend: a fast 
Table 3

Material constants obtained form Prony-series for collagenous materials.

\begin{tabular}{|c|c|c|c|c|c|}
\hline Specimen Type & $e_{1}$ & $e_{2}$ & $\tau_{1(\mathrm{~s})}$ & $\tau_{2(\mathrm{~s})}$ & References \\
\hline Fibrils & - & - & $1.8 \pm 0.2$ & $63 \pm 23$ & Yang et al. (2012b) \\
\hline Porcine skin & 0.34 & 0.32 & 52.6 & 2606 & Remache et al. (2018) \\
\hline Bones & 0.118 & 0.0351 & 7.70 & 1061.7 & Abdel-Wahab et al. (2011) \\
\hline This study & 0.31 & 0.13 & 64.8 & 1196 & \\
\hline
\end{tabular}

initial relaxation transformed into a monotonous decrease in the stress with increasing time. At $1000 \mathrm{~s}$, a drop in the stress of approximately $39 \%$ (from $36 \mathrm{MPa}$ to $22 \mathrm{MPa}$ ), $37 \%$ (from $46 \mathrm{MPa}$ to $29 \mathrm{MPa}$ ) and $32 \%$ (from $56 \mathrm{MPa}$ to $38 \mathrm{MPa}$ ) occurred for $1.40 \mathrm{~mm}, 1.92 \mathrm{~mm}$ and $2.52 \mathrm{~mm}$ deformation, respectively. However, the subsequent decline in the stress from $1000 \mathrm{~s}$ to $5400 \mathrm{~s}$ was relatively low $-13.6 \%$ (from $22 \mathrm{MPa}$ to 19 $\mathrm{MPa}$ ), $10.3 \%$ (from $29 \mathrm{MPa}$ to $26 \mathrm{MPa}$ ) and 8\% (from $38 \mathrm{MPa}$ to 35 $\mathrm{MPa}$ ), respectively. Moreover, from normalised curves (Fig. 9d), it was also observed that relaxation was faster when the collagen was strained at lower deformation. Similar response was observed in collagen fibrils (Shen et al., 2011) with a quicker relaxation time. Generally, the relaxation time depended on the scale, varying from nanoseconds in collagen molecules (Buehler, 2006a,b; Gautieri et al., 2009) to some $10 \mathrm{~s}$ in collagen fibrils (Shen et al., 2011) to some $1000 \mathrm{~s}$ in tissues (Remache et al., 2018; Abdel-Wahab et al., 2011), including collagen films in this study, which confirm that collagen hierarchy plays a significant role in stress relaxation. The viscoelastic response of a single fibril can be attributed to molecular rearrangement between collagen and water molecules (Shen et al., 2011), while at higher levels of the hierarchy, such as tendons and ligaments, this may be a result of the sliding mechanism of collagen fibres or fibrils (Screen, 2008) or uncrimping of the collagen fibres (Komatsu et al., 2007). Thus, it might be proposed that in collagen film two mechanisms - recruitment (unwinding and straightening) of fibres/fibrils and fibrils/fibres sliding - contributed to its stress-relaxation response.

\subsubsection{Parameter estimation of Prony series}

The normalised creep compliance obtained from experiments, for all (a)

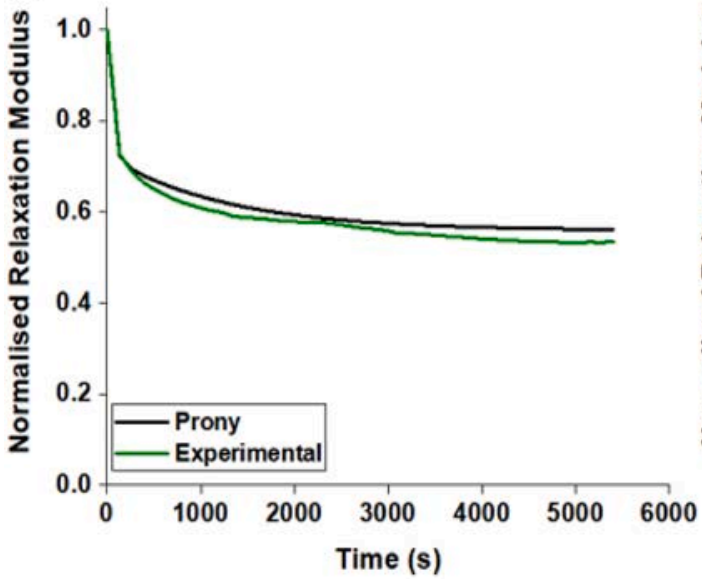

(b)

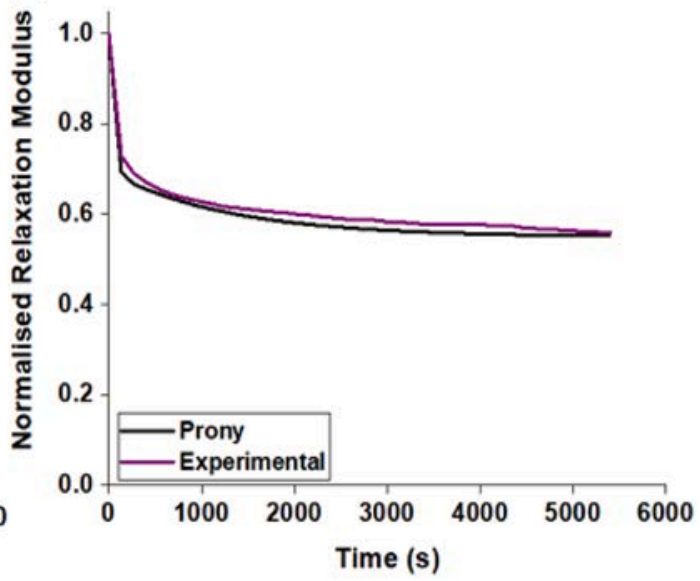

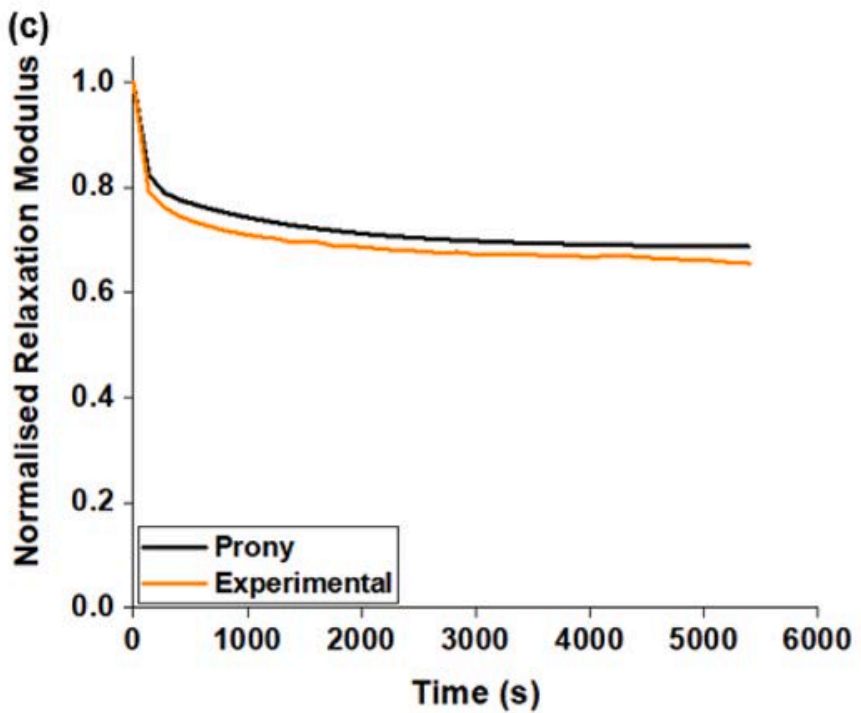

Fig. 11. Comparison between normalised relaxation modulus obtained with Abaqus and experimental data for various initial deformations: (a) 1.40 mm (corresponding to $40 \%$ of UTS); (b) $1.92 \mathrm{~mm}$ (corresponding to $50 \%$ of UTS); (c) $2.52 \mathrm{~mm}$ (corresponding to $60 \%$ of UTS). 
the employed loading conditions (40\%, 50\% and 60\% UTS), was fitted to extract an averaged normalised creep compliance curve (Fig. 10), to assess a single set of Prony-series constants (Table 3). The rapid decline in the contribution of subsequent terms in the Prony series allowed to limit analysis to the first two terms.

The relaxation moduli and times obtained for different collagenous materials vary significantly (Table 3). At microscopic level, the short relaxation time of fibrils is of the same order of magnitude as that of collagen embedded in hierarchical tissue (i.e. macroscopic level). This relaxation time was validated with both Maxwell-Weichert model (Shen et al., 2011) and estimation of Prony series parameter (Yang et al., $2012 b)$. In contrast, the relaxation times of complex tissues such as skin and bone were higher (greater than $1000 \mathrm{~s}$, Table 3). The long-term relaxation time obtained in this study was rather close to that of bones (Abdel-Wahab et al., 2011), while the short-term relaxation differed by an order of magnitude, as bone also contain hydroxyapatite. Alternatively, the short-term relaxation of skin (Remache et al., 2018) is close to the results of this study, while its long relaxation time varies due to the presence of ground substances such as proteoglycans (Shen et al., 2011). Also, the first modulus of skin is in close agreement to that obtained in this study.

The dimensionless normalised relaxation modulus calculated with Abaqus was compared with experimental data for initial stress levels corresponding to $40 \%, 50 \%$ and $60 \%$ of UTS. (Fig. 11). High levels of the coefficient of determination $\left(R^{2}>0.99\right)$ were found for all the loading conditions, validating the determined Prony-series coefficient. So, in this study, the Prony-series coefficients of pure collagen at higher levels of hierarchy were determined; they can be used in simulations of viscoelastic properties of collagenous materials.

\section{Conclusions}

Although previous studies demonstrated the inelastic and timedependent behaviour of collagenous tissues, there was a lack in the investigation of elasto-plastic and viscoelastic properties of pure collagen. This part of the work analysed the inelastic deformation and time-dependent behaviour of collagen under environmental conditions suitable for in-vivo biomedical applications. From the above experimental results, the main conclusions are:

- Cyclic loading with an increasing load amplitude resulted in an increase in the hardening behaviour of the collagen.

- For constant-amplitude cyclic loading, in-aqua samples demonstrated cyclic stiffening, with the growth of the modulus by about $50 \%$ at the end of 20th cycle in all the loading regimes, which may be attributed to the fibre orientation in the loading direction. On the contrary, in dry specimens, mechanical cycling resulted in a drop of the modulus - by $12 \%$ - (for high regime loading) after the 1 st cycle; thereafter, the modulus was insensitive to the increase in the mechanical cycling.

- Ratchetting strain accumulation was observed for both dry and inaqua cycling for all stress levels, as a result of plastic deformation.

- DMA tests provided in $\tan \delta$ values of $0.05-0.075$ for dry collagen films, approximately three times lower than those for hydrated collagen (0.12-0.24), demonstrating the effect of hydration that affected the interfibrillar bonds, leading to ductile regime as earlier reported for wet stratum corneum (Yuan and Verma, 2006).

- The time-dependent (creep) behaviour exhibited a rapid increase in the creep strain (primary creep) followed by a rather slow secondary regime. The stress relaxation followed a typical exponential decay behaviour: a fast initial relaxation was observed up to $1000 \mathrm{~s}$, leading to a slow reduction of stress.

- The experimental strain-time data obtained in tensile creep were used to extract the Prony series coefficients (relaxation moduli and times).

\section{CRediT authorship contribution statement}

Shirsha Bose: Investigation, Data curation, Writing - original draft. Simin Li: Conceptualization, Methodology, Writing - original draft. Elisa Mele: Conceptualization, Methodology, Writing - original draft. Vadim V. Silberschmidt: Conceptualization, Methodology, Writing original draft, Supervision.

\section{Declaration of competing interest}

The authors declare that they have no known competing financial interests or personal relationships that could have appeared to influence the work reported in this paper.

\section{Acknowledgement}

The authors would like to acknowledge the support provided by $\mathrm{Dr}$ Dani Abdo with implementation of the DMA tests.

\section{References}

Abdel-Wahab, A.A., Alam, K., Silberschmidt, V.V., 2011. Analysis of anisotropic viscoelastoplastic properties of cortical bone tissues. J. Mech. Behav. Biomed. Mater. 4 (5), 807-820. https://doi.org/10.1016/j.jmbbm.2010.10.001.

Abdo, D., Gleadall, A., Silberschmidt, V.V., 2019. Damage and damping of short-glassfibre-reinforced PBT composites under dynamic conditions: effect of matrix behaviour. Compos. Struct. 226, 111286. https://doi.org/10.1016/j. compstruct.2019.111286.

Anssari-Benam, A., Bader, D.L., Screen, H.R.C., 2011. Anisotropic time-dependant behaviour of the aortic valve. J. Mech. Behav. Biomed. Mater. 4 (8), 1603-1610. https://doi.org/10.1016/j.jmbbm.2011.02.010.

Ashby, M.F., 2011. Materials Selection in Mechanical Design, 4 th. Elsevier, New York. 4 th.

Ber, S., Torun Köse, G., Hasirci, V., 2005. Bone tissue engineering on patterned collagen films: an in vitro study. Biomaterials 26 (14), 1977-1986. https://doi.org/10.1016/ j.biomaterials.2004.07.007.

Bertassoni, L.E., Kury, M., Rathsam, C., Little, C.B., Swain, M.V., 2016. The role of proteoglycans in the nanoindentation creep behavior of human dentin. J. Mech. Behav. Biomed. Mater. 55, 264-270. https://doi.org/10.1016/j. jmbbm.2015.10.018.

Bose, S., Li, S., Mele, E., Silberschmidt, V.V., 2020. Dry vs. wet: properties and performance of collagen films. Part I. Mechanical behaviour and strain-rate effect. J. Mech. Behav. Biomed. Mater. 2020, 103983. https://doi.org/10.1016/j. jmbbm.2020.103983.

Buehler, M.J., 2006a. 'Atomistic and continuum modeling of mechanical properties of collagen : elasticity, fracture, and self-assembly'. J. Mater. Res. 21 (8), 1947-1961. https://doi.org/10.1557/JMR.2006.0236.

Buehler, M.J., 2006b. Nature designs tough collagen: explaining the nanostructure of collagen fibrils. Proc. Natl. Acad. Sci. Unit. States Am. 103 (33), 12285-12290. https://doi.org/10.1073/pnas.0603216103.

Collins, R.L.L., Christiansen, D., Zazanis, G.A., Silver, F.H., 1991. Use of collagen film as a dural substitute: preliminary animal studies. J. Biomed. Mater. Res. 25, 267-276. https://doi.org/10.1002/jbm.820250212.

Dong, X.N., Luo, Q., Wang, X., 2013. Progressive post-yield behavior of human cortical bone in shear. Bone 53 (1), 1-5. https://doi.org/10.1016/j.bone.2012.11.029.

Edupack, C.E., 2019. Granta Design, 2017. CES Edupack, 2017.

Fratzl, P., 2008. Collagen: Structure and Mechanics, an Introduction. In: Fratzl, P. (Ed.), Collagen: Structure and Mechanics. Springer, Boston, pp. 1-13.

Ganghoffer, J.F., Laurent, C., Maurice, G., Rahouadj, R., Wang, X., 2016. 'Nonlinear viscous behavior of the tendon's fascicles from the homogenization of viscoelastic collagen fibers'. Eur. J. Mech. 59, 265-279. https://doi.org/10.1016/j. euromechsol.2016.04.006. A/Solids.

Gao, L.L., Qin, X.Y., Zhang, C.Q., Gao, H., Ge, H.Y., Zhang, X.Z., 2015. Ratcheting behavior of articular cartilage under cyclic unconfined compression. Mater. Sci. Eng. C 57, 371-377. https://doi.org/10.1016/j.msec.2015.07.061.

Gautieri, A., Vesentini, S., Redaelli, A., Buehler, M.J., 2011. Hierarchical structure and nanomechanics of collagen microfibrils from the atomistic scale up. Nano Lett. 11 (2), 757-766. https://doi.org/10.1021/nl103943u.

Gautieri, A., Vesentini, S., Redaelli, A., Buehler, M.J., 2012. Viscoelastic properties of model segments of collagen molecules. Matrix Biol. 31 (2), 141-149. https://doi. org/10.1016/j.matbio.2011.11.005.

Gautieri, A., Vesentini, S., Redaelli, A., Ballarini, R., 2013. Modeling and measuring visco-elastic properties: from collagen molecules to collagen fibrils. Int. J. Non Lin. Mech. 56, 25-33. https://doi.org/10.1016/j.ijnonlinmec.2013.03.012.

Gautieri, A., Buehler, M.J., Redaelli, A., 2009. Deformation rate controls elasticity and unfolding pathway of single tropocollagen molecules. Journal of the Mechanical Behavior of Biomedical Materials 2 (2), 130-137. https://doi.org/10.1016/j. jmbbm.2008.03.001. 
Ghosh, S.K., Mandal, D., 2017. Sustainable energy generation from piezoelectric biomaterial for noninvasive physiological signal monitoring. ACS Sustain. Chem. Eng. 5 (10), 8836-8843. https://doi.org/10.1021/acssuschemeng.7b01617.

Hatami-Marbini, H., Rahimi, A., 2015. Collagen cross-linking treatment effects on corneal dynamic biomechanical properties. Exp. Eye Res. 135, 88-92. https://doi. org/10.1016/j.exer.2015.04.005.

Ibrahim, S., Kothapalli, C.R., Kang, Q.K., Ramamurthi, A., 2011. Characterization of glycidyl methacrylate - crosslinked hyaluronan hydrogel scaffolds incorporating elastogenic hyaluronan oligomers. Acta Biomater. 7, 653-665. https://doi.org/ 10.1016/j.actbio.2010.08.006.

Kadler, K.E., Baldock, C., Bella, J., Boot-Handford, R.P., 2007. Collagens at a glance. J. Cell Sci. 120 (12), 1955-1958. https://doi.org/10.1242/jcs.03453.

Kang, G., 2008. Ratchetting: recent progresses in phenomenon observation, constitutive modeling and application. Int. J. Fatig. 30 (8), 1448-1472. https://doi.org/10.1016/ j.ijfatigue.2007.10.002.

Kang, G., Liu, Y., 2008. Uniaxial ratchetting and low-cycle fatigue failure of the steel with cyclic stabilizing or softening feature. Mater. Sci. Eng. 472 (1-2), 258-268. https:// doi.org/10.1016/j.msea.2007.03.029.

Kang, G., Wu, X., 2011. Ratchetting of porcine skin under uniaxial cyclic loading. Journal of the Mechanical Behavior of Biomedical Materials 4 (3), 498-506. https://doi.org/ 10.1016/j.jmbbm.2010.12.015.

Kocen, R., Gasik, M., Gantar, A., Novak, S., 2017. Viscoelastic behaviour of hydrogelbased composites for tissue engineering under mechanical load. Biomed. Mater. 12 (2), 025004 https://doi.org/10.1088/1748-605X/aa5b00.

Komatsu, K., Sanctuary, C., Shibata, T., Shimada, A., Botsis, J., 2007. 'Stress - relaxation and microscopic dynamics of rabbit periodontal ligament'. J. Biomech. 40, 634-644. https://doi.org/10.1016/j.jbiomech.2006.01.026.

Lee, K.Y., Mooney, D.J., 2001. Hydrogels for tissue engineering. Chem. Rev. 101 (7) https://doi.org/10.1021/cr000108x.

Li, S., Liu, W.C., Chang, Y.H., Liu, X., Chang, C.L., Lin, C., Chung, R.J., 2019. Preparation and in vivo investigation of oligomeric proanthocyanidins cross-linked collagen serving as synthesized tissue regeneration membrane. Mater. Sci. Eng. C 101, 640-649. https://doi.org/10.1016/j.msec.2019.03.112.

Liu, J., Das, D., Yang, F., Schwartz, A.G., Genin, G.M., Thomopoulos, S., Chasiotis, I. 2018. Energy dissipation in mammalian collagen fibrils: cyclic strain-induced damping, toughening, and strengthening. Acta Biomater. 80, 217-227. https://doi. org/10.1016/j.actbio.2018.09.027.

Liu, Y., Ren, L., Yao, H., Wang, Y., 2012. Collagen films with suitable physical properties and biocompatibility for corneal tissue engineering prepared by ion leaching technique. Mater. Lett. 87, 1-4. https://doi.org/10.1016/j.matlet.2012.07.091.

Liu, Y., Ren, L., Long, K., Wang, L., Wang, Y., 2014. Preparation and characterization of a novel tobramycin-containing antibacterial collagen film for corneal tissue engineering. Acta Biomater. 10 (1), 289-299. https://doi.org/10.1016/j actbio.2013.08.033.

Maeda, M., Kadota, K., Kajihara, M., Sano, A., Fujioka, K., 2001. Sustained release of human growth hormone (hGH) from collagen film and evaluation of effect on wound healing in db/db mice. J. Contr. Release 77 (3), 261-272. https://doi.org/10.1016/ S0168-3659(01)00512-0.

Moreno, S., Baniasadi, M., Mohammed, S., Mejia, I., Chen, Y., Quevedo-Lopez, M.A., Kumar, N., Dimitrijevich, S., Minary-Jolandan, M., 2015. Biocompatible collage films as substrates for flexible implantable electronics. Adv. Electron. Mater. 1 (9), 1500154. https://doi.org/10.1002/aelm.201500154.

Muñoz, M.J., Bea, J.A., Rodríguez, J.F., Ochoa, I., Grasa, J., Pérez del Palomar, A., Zaragoza, P., Osta, R., Doblaré, M., 2008. An experimental study of the mouse skin behaviour: damage and inelastic aspects. J. Biomech. 41 (1), 93-99. https://doi.org/ 10.1016/j.jbiomech.2007.07.013.

Novitskaya, E., Zin, C., Chang, N., Cory, E., Chen, P., D'Lima, D., Sah, R.L., McKittrick, J., 2014. Creep of trabecular bone from the human proximal tibia. Mater. Sci. Eng. C 40, 219-227. https://doi.org/10.1016/j.msec.2014.03.057.

Oechsle, A.M., Bugbee, T.J., Gibis, M., Kohlus, R., Weiss, J., 2017. Modification of extruded chicken collagen films by addition of co-gelling protein and sodium chloride. J. Food Eng. 207, 46-55. https://doi.org/10.1016/j.jfoodeng.2017.03.017.
Pathak, S., Gregory Swadener, J., Kalidindi, S.R., Courtland, H.W., Jepsen, K.J., Goldman, H.M., 2011. Measuring the dynamic mechanical response of hydrated mouse bone by nanoindentation. Journal of the Mechanical Behavior of Biomedical Materials 4 (1), 34-43. https://doi.org/10.1016/j.jmbbm.2010.09.002.

Payne, T., Mitchell, S., Bibb, R., Waters, M., 2015. The evaluation of new multi-material human soft tissue simulants for sports impact surrogates. Journal of the Mechanical Behavior of Biomedical Materials 41, 336-356. https://doi.org/10.1016/j. jmbbm.2014.09.018.

Pissarenko, A., Yang, W., Quan, H., Brown, K.A., Williams, A., Proud, W.G., Meyers, M. A., 2019. Tensile behavior and structural characterization of pig dermis. Acta Biomater. 86, 77-95. https://doi.org/10.1016/j.actbio.2019.01.023.

Rath, A., Mathesan, S., Ghosh, P., 2016. Nanomechanical characterization and molecular mechanism study of nanoparticle reinforced and cross-linked chitosan biopolymer. J. Mech. Behav. Biomed. Mater. 55, 42-52. https://doi.org/10.1016/j. jmbbm.2015.10.005.

Remache, D., Caliez, M., Gratton, M., Dos Santos, S., 2018. The effects of cyclic tensile and stress-relaxation tests on porcine skin. J. Mech. Behav. Biomed. Mater. 77, 242-249. https://doi.org/10.1016/j.jmbbm.2017.09.009.

Sang, J., Li, X., Shao, Y., Li, Z., Fu, J., 2017. Controlled tubular unit formation from collagen film for modular tissue engineering. ACS Biomater. Sci. Eng. 3 (11), 2860-2868. https://doi.org/10.1021/acsbiomaterials.6b00468.

Screen, H.R.C., 2008. Investigating load relaxation mechanics in tendon. J. Mech. Behav. Biomed. Mater. 1 (1), 51-58. https://doi.org/10.1016/j.jmbbm.2007.03.002.

Shen, Z.L., Kahn, H., Ballarini, R., Eppell, S.J., 2011. Viscoelastic properties of isolated collagen fibrils. Biophys. J. 100 (12), 3008-3015. https://doi.org/10.1016/j. bpj.2011.04.052.

Shepherd, J.H., Legerlotz, K., Demirci, T., Klemt, C., Riley, G.P., Screen, H.R.C., 2014 Functionally distinct tendon fascicles exhibit different creep and stress relaxation behaviour. Proc. IME H J. Eng. Med. 228 (1), 49-59. https://doi.org/10.1177/ 0954411913509977.

Su, W.R., Chen, H.H., Luo, Z.P., 2008. Effect of cyclic stretching on the tensile properties of patellar tendon and medial collateral ligament in rat. Clin. BioMech. 23 (7), 911-917. https://doi.org/10.1016/j.clinbiomech.2008.04.002.

Susilo, M.E., Paten, J.A., Sander, E.A., Nguyen, T.D., Ruberti, J.W., 2016. Collagen network strengthening following cyclic tensile loading. Interface Focus 6 (1). https://doi.org/10.1098/rsfs.2015.0088.

Sweeney, A.K., Byers, R.K., Kroon, R.P., 1965. Mechanical characteristics of bone and its constituents. Mech. Eng. 87 (12), 62

Venugopal, G., Veetil, J.C., Raghavan, N., Singh, V., Kumar, A., Mukkannan, A., 2016. Nano-dynamic mechanical and thermal responses of single-walled carbon nanotubes reinforced polymer nanocomposite thinfilms. J. Alloys Compd. 688, 454-459. https://doi.org/10.1016/j.jallcom.2016.07.209.

de Vries, A., Wesseling, A., van der Linden, E., Scholten, E., 2017. Protein oleogels from heat-set whey protein aggregates. J. Colloid Interface Sci. 486, 75-83. https://doi. org/10.1016/j.jcis.2016.09.043.

Wilcox, A.G., Buchan, K.G., Espino, D.M., 2014. Frequency and diameter dependent viscoelastic properties of mitral valve chordae tendineae. J. Mech. Behav. Biomed. Mater. 30, 186-195. https://doi.org/10.1016/j.jmbbm.2013.11.013.

Wineman, A.S., Rajagopal, K.R., 2000. Mechanical Response of Polymers: an Introduction. Cambridge University Press.

Yang, B., Zhang, Y., Zhang, X., Tao, L., Li, S., Wei, Y., 2012a. Facilely prepared inexpensive and biocompatible self-healing hydrogel: a new injectable cell therapy carrier. Polym. Chem. 3 (12), 3235-3238. https://doi.org/10.1039/c2py20627g.

Yang, L., van der Werf, K.O., Dijkstra, P.J., Feijen, J., Bennink, M.L., 2012 b. Micromechanical analysis of native and cross-linked collagen type I fibrils supports the existence of microfibrils. J. Mech. Behav. Biomed. Mater. 6, 148-158. https:// doi.org/10.1016/j.jmbbm.2011.11.008.

Yuan, Y., Verma, R., 2006. Measuring microelastic properties of stratum corneum. Colloids Surf. B Biointerfaces 48 (1), 6-12. https://doi.org/10.1016/j. colsurfb.2005.12.013. 